\title{
Transient Climate Change Simulations with a Coupled Atmosphere-Ocean GCM Including the Tropospheric Sulfur Cycle
}

\author{
E. Roeckner, L. Bengtsson, And J. Feichter \\ Max Planck Institute for Meteorology, Hamburg, Germany \\ J. LELIEVELD \\ Institute for Marine and Atmospheric Research Utrecht, Utrecht, Netherlands \\ H. RODHE \\ Department of Meteorology, Stockholm University, Sweden
}

(Manuscript received 14 August 1998, in final form 18 December 1998)

ABSTRACT

\begin{abstract}
The time-dependent climate response to changing concentrations of greenhouse gases and sulfate aerosols is studied using a coupled general circulation model of the atmosphere and the ocean (ECHAM4/OPYC3). The concentrations of the well-mixed greenhouse gases like $\mathrm{CO}_{2}, \mathrm{CH}_{4}, \mathrm{~N}_{2} \mathrm{O}$, and CFCs are prescribed for the past (1860-1990) and projected into the future according to International Panel on Climate Change (IPCC) scenario IS92a. In addition, the space-time distribution of tropospheric ozone is prescribed, and the tropospheric sulfur cycle is calculated within the coupled model using sulfur emissions of the past and projected into the future (IS92a). The radiative impact of the aerosols is considered via both the direct and the indirect (i.e., through cloud albedo) effect. It is shown that the simulated trend in sulfate deposition since the end of the last century is broadly consistent with ice core measurements, and the calculated radiative forcings from preindustrial to present time are within the uncertainty range estimated by IPCC. Three climate perturbation experiments are performed, applying different forcing mechanisms, and the results are compared with those obtained from a $300-\mathrm{yr}$ unforced control experiment. As in previous experiments, the climate response is similar, but weaker, if aerosol effects are included in addition to greenhouse gases. One notable difference to previous experiments is that the strength of the Indian summer monsoon is not fundamentally affected by the inclusion of aerosol effects. Although the monsoon is damped compared to a greenhouse gas only experiment, it is still more vigorous than in the control experiment. This different behavior, compared to previous studies, is the result of the different land-sea distribution of aerosol forcing. Somewhat unexpected, the intensity of the global hydrological cycle becomes weaker in a warmer climate if both direct and indirect aerosol effects are included in addition to the greenhouse gases. This can be related to anomalous net radiative cooling of the earth's surface through aerosols, which is balanced by reduced turbulent transfer of both sensible and latent heat from the surface to the atmosphere.
\end{abstract}

\section{Introduction}

Coupled general circulation models of the atmosphere and ocean (AOGCM's) have been used to study the evolution of the earth's climate since the beginning of the industrial revolution, associated with changing atmospheric concentrations of both greenhouse gases and sulfate aerosols (Hasselmann et al. 1995; Mitchell et al. 1995a; Johns et al. 1997; Meehl et al. 1996; Hegerl et al. 1997; Mitchell and Johns 1997; Haywood et al. 1997). These studies have confirmed the conclusions

Corresponding author address: Dr. E. Roeckner, Max Planck Institute for Meteorology, Bundesstrasse 55, 20146 Hamburg, Germany. E-mail: roeckner@dkrz.de from equilibrium response studies with simplified models (Taylor and Penner 1994; Mitchell et al. 1995b; Roeckner et al. 1995; Erickson et al. 1995; Le Treut et al. 1996), that anthropogenic sulfate aerosols have the potential to significantly modify greenhouse warming. Moreover, it was shown that the simulated temperature trends in recent decades are in better agreement with observations if the simulations do not only allow for changes in greenhouse gases but also for those in aerosols (Hasselmann et al. 1995; Mitchell et al. 1995a; Johns et al. 1997; Hegerl et al. 1997; Haywood et al. 1997).

In these time-dependent response studies several simplifications were made. First, the annual mean column burden of anthropogenic sulfate was precalculated with a chemical-transport model (e.g., Langner and Rodhe 
1991) and subsequently prescribed in the AOGCM. The meteorological variables used for driving the chemicaltransport model, such as wind, temperature, and precipitation, were based on observed climatologies rather than the actual "weather" simulated by the AOGCM. This approach does not only eliminate weather-type fluctuations of aerosols but also, and more importantly, aerosol-climate interactions on longer timescales. Second, the so-called direct radiative effect of aerosols due to backscattering of solar radiation in clear skies is simply expressed as a perturbation of the surface albedo depending on the total sulfate aerosol burden in the atmospheric column (Charlson et al. 1991). Furthermore, since aerosols codetermine the microphysical and radiative properties of clouds, increased aerosol concentrations can enhance both the cloud albedo (Twomey 1977) and the cloud lifetime (Albrecht 1989). These socalled indirect aerosol effects were mostly neglected in transient climate simulations or treated in a highly idealized way (Meehl et al. 1996).

In this study, we use an AOGCM, which does not suffer from the simplifications mentioned above. It includes a sulfur cycle model, which is driven by prescribed emissions at the surface and internal processes such as sulfur chemistry, transport, and deposition. The radiative coupling between the model-generated sulfate aerosols and the climate system is via both direct and indirect effects. For estimating the direct effect, the aerosol optical properties are derived from Mie theory. The computation of the indirect effect is based on empirical relationships between cloud droplet number concentration and aerosol abundance. The cloud lifetime effect is neglected. The model also includes the radiative forcing due to precalculated changes in tropospheric ozone. Moreover, unlike previous studies in which the radiative effect of the well-mixed greenhouse gases is approximated by prescribing an effective carbon dioxide $\left(\mathrm{CO}_{2}\right)$ concentration, the concentrations of $\mathrm{CO}_{2}$, methane $\left(\mathrm{CH}_{4}\right)$, nitrous oxide $\left(\mathrm{N}_{2} \mathrm{O}\right)$, several chlorofluorocarbons (CFCs), and CFC substitute gases are explicitly prescribed. Although the model includes the most important anthropogenic constitutents relevant for the climate evolution in the past and future (IPCC 1996), the sulfate aerosol forcing is just a subset of the total. Anthropogenic forcing from aerosol species other than sulfate-like carbonaceous aerosols (Penner et al. 1992; Haywood and Shine 1995; Schult et al. 1997) and mineral dust from disturbed soils (Tegen et al. 1996) are neglected in our model as well as stratospheric ozone depletion (Ramaswamy et al. 1996). Finally, one should keep in mind that the confidence in estimates of the aerosol radiative forcing is low. This applies especially for the indirect effect (IPCC 1996).

In this study, we discuss three time-dependent forcing experiments in which observed (1860-1990) and projected (1990-2050) changes in greenhouse gas concentrations and sulfur emissions are prescribed. While a comparison with observed temperature trends was pre- sented by Bengtsson et al. (1999), and the impact of greenhouse warming on ENSO statistics by Timmermann et al. (1999), this paper primarily deals with possible future atmospheric changes, with emphasis on aerosol impacts. The response of the ocean will be the subject of a separate study. The three model components, that is, the atmospheric GCM (AGCM), the sulfur cycle model, and the ocean GCM (OGCM) are briefly described in section 2 and the experiments are outlined in section 3. The results are documented and discussed in sections 4 (sulfur simulation), 5 (radiative forcing), and 6 (climate response). Finally, a summary and the main conclusions are presented in section 7 .

\section{Model description}

The AOGCM used in this study consists of the following components.

The atmospheric component is the ECHAM4 model Roeckner et al. (1996a). It employs a 19-level hybrid sigma-pressure coordinate system, and the vertical domain extends up to the pressure level of $10 \mathrm{hPa}$. Prognostic variables are vorticity, divergence, logarithm of surface pressure, temperature, specific humidity, and mixing ratio of total cloud water. Apart from positive definite quantities, the prognostic variables are represented by spherical harmonics with triangular truncation at wavenumber 42 (T42). For the advection of water vapor, cloud water, and chemical constituents, a semiLagrangian scheme (Williamson and Rasch 1994) is used. The time step for dynamics and physics is $24 \mathrm{~min}$ while the radiation time step is $2 \mathrm{~h}$. Both seasonal and diurnal cycles in solar forcing are simulated. The turbulent surface fluxes are calculated from Monin-Obukhov similarity theory (Louis 1979), and a higher-order closure scheme (Brinkop and Roeckner 1995) is used to compute the vertical diffusion of momentum, heat, moisture, cloud water, sulfate aerosols, and gaseous sulfur compounds. The drag associated with orographic gravity waves is simulated after Miller et al. (1989). The soil model comprises the budgets of heat and water in the soil, the snowpack over land and the heat budget of land ice. The parameterization of cumulus convection is based on the bulk mass flux concept of Tiedtke (1989) as modified by Nordeng (1994). The stratiform cloud water content is calculated from the respective budget equation including sources and sinks due to phase changes, detrainment of convectively generated cloud water, and precipitation formation by coalescence of cloud droplets and gravitational settling of ice crystals (Roeckner 1995). The transfer of solar radiation is parameterized after Fouquart and Bonnel (1980) and the transfer of longwave radiation after Morcrette et al. (1986). The original radiation scheme is modified to include additional greenhouse gases $\left(\mathrm{CH}_{4}, \mathrm{~N}_{2} \mathrm{O}\right.$, and several CFCs, HCFCs, and HFCs) and also the 14.6$\mu \mathrm{m}$ band of ozone. Single-scattering properties of cloud droplets and ice crystals are derived from Mie theory 
and adapted to the broadband model (Rockel et al. 1991), and the effective radius of cloud droplets and ice crystals is parameterized in terms of the liquid and ice water content, respectively (Roeckner 1995).

In the model of the tropospheric sulfur cycle (Feichter et al. 1996, 1997) basic processes such as transport and deposition, and also the chemistry in parts, are calculated interactively with the ECHAM4 model. Prognostic variables are dimethylsulfide (DMS) and sulfur dioxide $\left(\mathrm{SO}_{2}\right)$ as gases and sulfate $\left(\mathrm{SO}_{4}^{2-}\right)$ as aerosol. Biogenic emissions from oceans, soils, and plants are assumed to occur as DMS while emissions from noneruptive volcanoes, biomass burning, combustion of fossil fuel and from smelting are assumed to occur as $\mathrm{SO}_{2}$. Advective transport as well as vertical diffusion and convective transport are treated analogously to water vapor. The dry deposition flux to the ground is a function of the respective concentration in the lowest model layer $(\sim 30$ $\mathrm{m}$ above surface) and a deposition velocity that depends on the sulfur compound $\left(\mathrm{SO}_{2}, \mathrm{SO}_{4}^{2-}\right)$ and the state of the surface (water, ice, snow, soil wetness). Precipitation scavenging of $\mathrm{SO}_{2}$ and $\mathrm{SO}_{4}^{2-}$ is calculated in terms of the local precipitation formation rate. DMS and $\mathrm{SO}_{2}$ are oxidized by reaction with hydroxyl radicals $(\mathrm{OH})$ during the day. Additionally, DMS reacts with nitrate radicals $\left(\mathrm{NO}_{3}\right)$ during the night. Dissolution of $\mathrm{SO}_{2}$ in cloud water is calculated according to Henry's law. In the aqueous phase, we consider the oxidation of $\mathrm{SO}_{2}$ by hydrogen peroxide $\left(\mathrm{H}_{2} \mathrm{O}_{2}\right)$ and ozone $\left(\mathrm{O}_{3}\right)$. These components are not calculated interactively in ECHAM4 but prescribed, as monthly mean three-dimensional distributions, according to estimates of a more comprehensive chemistry model coupled to ECHAM4 (Roelofs and Lelieveld 1995). The end product of the gaseous and aqueous oxidation of $\mathrm{SO}_{2}$ is sulfate aerosol $\left(\mathrm{SO}_{4}^{2-}\right)$. The radiative interactions with the AGCM through both the direct and indirect aerosol effects are described together with the respective experiments in section 3 .

The oceanic component of the coupled model is an extended version (level 3) of the OPYC model (Oberhuber 1993). It consists of three submodels for the interior ocean, the surface mixed layer, and sea ice. The model has 11 layers. Poleward of $36^{\circ}$, the horizontal resolution is identical to that of the atmospheric model ( $\sim 2.8^{\circ}$, equivalent to the T42 Gaussian grid). At lower latitudes, the meridional grid spacing is gradually decreased down to $0.5^{\circ}$ at the equator. The submodel for the interior ocean employs the primitive equations in the flux form of the conservation laws for momentum, mass, heat, and salt in isopycnal layers. Horizontal mixing for momentum is a function of the local Rossby deformation radius, while horizontal diffusion for temperature and salinity involves some dependence on flow deformation. Vertical mixing follows the concept of entrainment/detrainment for which budgets of turbulent and mean potential energy are solved. A standard convection scheme is used that instantaneously removes vertical instabilities. The model for the interior ocean
TABLE 1. List of experiments.

\begin{tabular}{llc}
\hline \hline Acronym & \multicolumn{1}{c}{$\begin{array}{c}\text { Forcing due to changing } \\
\text { atmospheric concentrations of ... }\end{array}$} & Years \\
\hline GHG & $\begin{array}{l}\mathrm{CO}_{2} \text { and other well-mixed green- } \\
\text { house gases }\end{array}$ & $1860-2100$ \\
GSD & $\begin{array}{l}\text { GHG plus sulfate aerosols (direct } \\
\text { effect only) }\end{array}$ & $1860-2050$ \\
GSDIO & $\begin{array}{l}\text { GHG plus sulfate aerosols (direct } \\
\text { and indirect effect) plus tropo- } \\
\text { spheric ozone }\end{array}$ & $1860-2050$ \\
CTL & \begin{tabular}{l} 
Unforced control experiment \\
\hline
\end{tabular}
\end{tabular}

is coupled to a surface mixed-layer model that computes entrainment rates out of an isopycnal layer or detrainment rates into an isopycnal layer according to a budget equation for turbulent kinetic and mean potential energy. The sea-ice model solves for ice momentum, ice and snow thickness, and ice concentration. A viscous-plastic rheology is used to parameterize the stress tensor.

The model components are coupled quasi-synchronously and exchange information once a day. The AGCM provides daily-averaged surface fluxes of momentum, heat, freshwater, etc., for the OGCM, which returns daily-averaged sea surface temperature and seaice variables to the AGCM. Annual mean flux adjustments of heat and freshwater were estimated from a 100yr coupled model spinup. More details on the coupling technique and on the performance of the model can be found in Roeckner et al. (1996b) and Bacher et al. (1998).

\section{Design of experiments}

In addition to an unforced control experiment (CTL), we have performed three time-dependent forcing experiments (see Table 1).

\section{a. Control experiment}

In CTL, greenhouse gases and aerosols are prescribed exactly as in the uncoupled ECHAM4 model. The concentrations of carbon dioxide, methane, and nitrous oxide are fixed at the observed 1990 values (IPCC 1990, their Table 2.5), the concentrations of the industrial gases (CFCs and others) are set to zero, while ozone and aerosols are prescribed as climatological distributions. There is no sulfur cycle in CTL. After a 100-yr spinup the model was run, with constant flux adjustment, for another $300 \mathrm{yr}$. The climatology constructed from this 300-yr CTL run serves as a reference for the time-dependent forcing experiments GHG, GSD, and GSDIO.

\section{b. Experiment $G H G$}

In GHG, the concentrations of the following greenhouse gases are prescribed as a function of time: $\mathrm{CO}_{2}$, $\mathrm{CH}_{4}, \mathrm{~N}_{2} \mathrm{O}$, and several industrial gases such as chlorofluorocarbons (CFC-11, 12, 113, 114, 115); hydro- 
chlorofluorocarbons (HCFC-22, 123, 141b); hydrofluorocarbons (HFC-125, 134a, 152a); carbon tetrachloride $\left(\mathrm{CCl}_{4}\right)$ and methylchloroform $\left(\mathrm{CH}_{3} \mathrm{CCl}_{3}\right)$. From 1860 to 1990 , the annual concentrations of these gases are prescribed as observed and, from 1990 onward, according to scenario IS92a (IPCC 1992). For the industrial gases, the IS92a scenario is updated to be consistent with a Copenhagen-like emission scenario (IPCC 1996). All of the time dependent, or "transient," forcing experiments were initialized at year 100 of CTL, nominally 1860 in the transient experiments. Because present-day observations were employed for ocean spinup and for deriving the flux adjustment (Bacher et al. 1998), we have to realize that the CTL climate and, hence, the initial state in the transient experiments does not correspond to preindustrial but to modern time. Furthermore, in CTL, 1990 concentrations of $\mathrm{CO}_{2}, \mathrm{CH}_{4}$, and $\mathrm{N}_{2} \mathrm{O}$ are used rather than preindustrial ones. In the transient experiments, the initial shift in concentrations is taken into account by enhancing the observed/projected concentrations of these gases in an appropriate way (see appendix). Although this approach allows for a reasonably correct computation of the radiative forcing, it does not account for the warm bias in the initial state. This initial warm bias, compared to the observations, is maintained throughout the simulation and, therefore, does not affect climatic trends.

\section{c. Experiment GSD}

In GSD, the greenhouse gases are treated as in GHG but the tropospheric sulfur cycle, with anthropogenic sources only, is simulated in addition. As in GHG and CTL, the background aerosol is prescribed as a climatological distribution. Natural biogenic and volcanic sulfur emissions are neglected so that the aerosol radiative forcing is generated through the anthropogenic part of the sulfur cycle. The space-time evolution in the sulfur emissions due to fossil fuel use and industry was derived from various sources: for the years $1860,1870, \ldots$, 1970 we use estimates of Örn et al. (1996); for 1980 those of Spiro et al. (1992); while scenario IS92a is used for the years 1990, 2000, . . , 2050 (IPCC 1992).

Sulfur emissions from biomass burning are very small, and the historical estimates are very uncertain. We assume that the biomass burning emissions of sulfur in 1860 are $10 \%$ of the present, which amounts to about 2.5 $\mathrm{Tg} \mathrm{S} \mathrm{yr}^{-1}$ globally (Hao et al. 1990), and we also assume that there will be no change in the future of this source. For comparison, the annual global emissions due to fossil fuel burning and industry increase from roughly $10 \mathrm{Tg} \mathrm{S}$ in 1900 to about $75 \mathrm{Tg} \mathrm{S}$ in 1995 and finally, according to IS92a, to $150 \mathrm{Tg} \mathrm{S}$ in 2050. The total anthropogenic emissions used in GSD (and also in GSDIO, see below) are obtained by linear interpolation between the data points (Fig. 1).

In GSD only the direct radiative effect of the aerosols is included. For computing the aerosol optical proper-

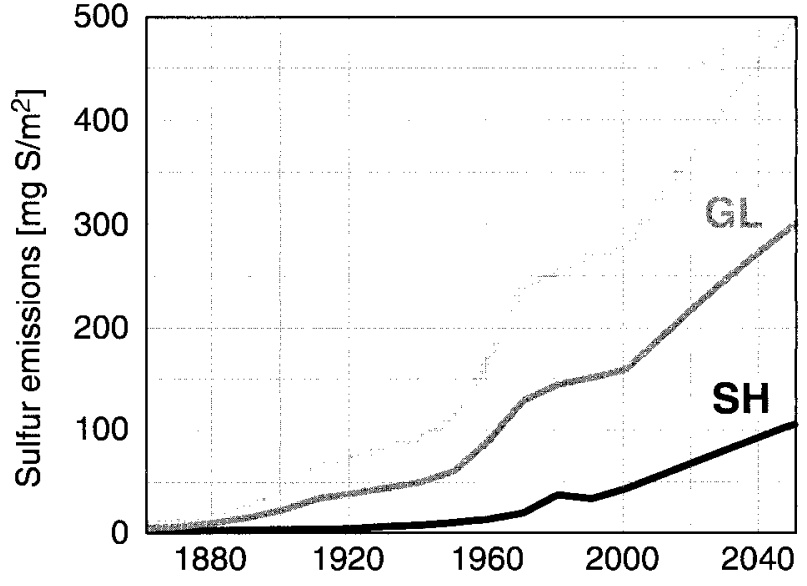

FIG. 1. Historical and future anthropogenic sulfur (S) emissions in the Northern Hemisphere $(\mathrm{NH})$, in the Southern Hemisphere $(\mathrm{SH})$, and for the globe (GL), as prescribed in experiments GSD and GSDIO (see section 3). Units are $\mathrm{mg} \mathrm{S} \mathrm{m}^{-2}$.

ties, the model-generated $d r y$ sulfate mass mixing ratio is transformed into particle number concentrations by assuming a lognormal size distribution with a mode radius of $r_{m}=0.07 \mu \mathrm{m}$, geometric standard deviation of 2.03 , and density $\rho=1.7 \mathrm{~g} \mathrm{~cm}^{-3}$. Since the current version of the model does not include the dependency of particle size on ambient humidity, we assumed a constant relative humidity of $\mathrm{RH}=80 \%$ with $r_{m}=$ $0.118 \mu \mathrm{m}$ and $\rho=1.14 \mathrm{~g} \mathrm{~cm}^{-3}$ (Köpke et al. 1997). The resulting mass-scattering efficiency at $0.55 \mu \mathrm{m}$ is $3.41 \mathrm{~m}^{2} \mathrm{~g}^{-1}$. However, since the dominant chemical form of sulfate aerosols in the troposphere may be ammonium sulfate or ammonium bisulfate, the aerosol mass associated with sulfate is higher than the mass of the sulfate ions alone. Therefore, the mass-scattering efficiency of dry sulfate at $0.55 \mu \mathrm{m}$ is enhanced to 5.0 $\mathrm{m}^{2} \mathrm{~g}^{-1}$ (Feichter et al. 1997), in accordance with measurements (Charlson et al. 1991) and previous model calculations (Kiehl and Briegleb 1993). The simplifying assumption of RH $=80 \%$ causes an overestimation of the direct sulfate effect in dry regions while in wet regions $(\mathrm{RH}>80 \%)$ the direct effect is underestimated. Since $\mathrm{RH}<80 \%$ in most areas, the global mean direct effect might be overestimated by almost $30 \%$ (Feichter et al. 1997).

\section{d. Experiment GSDIO}

GSDIO differs from GSD in two respects; first, the indirect effect of sulfate aerosol on cloud albedo is taken into account in a parameterized manner and, second, the tropospheric ozone distribution is allowed to change as a result of prescribed anthropogenic emissions of precursor gases. In ECHAM4, the single-scattering properties of water droplets and "equivalent" ice spheres are derived from Mie theory, the results are fitted to the spectral resolution of the broadband radiation code and 
formulated in terms of cloud droplet and ice crystal effective radii. For liquid clouds, the mean volume radius $\left(r_{v}\right)$ is obtained from the cloud water mixing ratio in the cloudy part of the grid box $\left(q_{l} / b\right)$, where $q_{l}$ is the model-predicted grid-averaged cloud water mixing ratio and $b$ is fractional cloud cover, and the cloud droplet number concentration $N_{c}$

$$
r_{v}=\sqrt[3]{\frac{3 q_{l}}{4 \pi \rho_{l} b N_{c}}},
$$

where $\rho_{l}$ is water density. On the basis of measurements, Johnson (1993) suggested a linear relationship between $r_{v}$ and the cloud droplet effective radius, $r_{e}=k r_{v}$, with $k=1.14$ for continental clouds and $k=1.08$ for maritime clouds.

In CTL, $N_{c}$ is prescribed differently for continental clouds $\left[N_{c}(\mathrm{con})=220 \mathrm{~cm}^{-3}\right]$ and maritime clouds $\left[N_{c}\right.$ (mar) $\left.=100 \mathrm{~cm}^{-3}\right]$. Above the atmospheric boundary layer, $N_{c}$ is assumed to decrease exponentially with height, approaching a value of $50 \mathrm{~cm}^{-3}$ in the upper troposphere for both continental and maritime clouds.

In GSDIO, $N_{c}$ is variable in space and time. The indirect aerosol effect is realized via empirical relationships between $N_{c}$ and the sulfate aerosol mass mixing ratio $\mathrm{SO}_{4}^{2-}$ (Lohmann and Feichter 1997), with $\mathrm{SO}_{4}^{2-}$ in

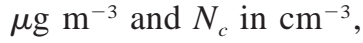

$$
\begin{aligned}
& \log N_{c}(\text { mar })=a_{m}+b_{m}\left(\log \mathrm{SO}_{4}^{2-}\right), \\
& \log N_{c}(\text { con })=a_{c}+b_{c}\left(\log \mathrm{SO}_{4}^{2-}\right),
\end{aligned}
$$

where $a_{m}=2.06, b_{m}=0.48, a_{c}=2.24$, and $b_{c}=0.26$. The measurements on which (2) and (3) are based suggest that increasing levels of sulfate aerosol mass concentrations in the atmosphere would enhance the number of cloud condensation nuclei and, therefore, $N_{c}$. According to Eq. (1), this would cause a decrease of $r_{e}$ and, hence, an increase of cloud optical depth under the assumption that the liquid water content remains unchanged. As in GSD, $\mathrm{SO}_{4}^{2-}$ is obtained from the sulfur cycle model but there is one basic difference. While the direct effect in GSD, with respect to CTL, can be estimated from the anthropogenic sulfur sources alone, and vanishes as soon as the anthropogenic sources are switched off, an analogous perturbation method is no longer applicable in GSDIO. Here, for $\mathrm{SO}_{4}^{2-}$ (anth) $=0$ the indirect effect would not vanish because the $N_{c}$ distribution obtained from Eqs. (2) and (3) would not be identical to the $N_{c}$ distribution applied in CTL. Therefore, the anthropogenic perturbation of CTL is estimated from two simulations of the sulfur cycle with identical meteorological input at the concurrent time step. In the first loop, the natural distribution $\mathrm{SO}_{4}^{2-}$ (nat) is computed by using the natural sulfur sources alone (DMS and volcanoes). In the second loop, $\mathrm{SO}_{4}^{2-}$ (all) is obtained from all sources, natural and anthropogenic. This allows us to compute the single-scattering properties (SSP) of cloud droplets, via Eqs. (1) to (3), for both natural sulfate, $\operatorname{SSP}($ nat), and total sulfate, $\operatorname{SSP}($ all). The reference
SSP are computed as in the control experiment, using prescribed $N_{c}$, so that the cloud SSP employed in GSDIO is defined as

$$
\mathrm{SSP}(\mathrm{GSDIO})=\mathrm{SSP}(\mathrm{CTL})+\mathrm{SSP}(\text { all })-\mathrm{SSP}(\text { nat }) \text {, }
$$

where $\operatorname{SSP}($ all) - $\mathrm{SSP}$ (nat) is the anthropogenic perturbation of CTL. It vanishes, as required, if all anthropogenic sources are switched off. Consistent with Eq. (4), the direct effect in GSDIO is estimated from the difference $\mathrm{SO}_{4}^{2-}$ (anth) $=\mathrm{SO}_{4}^{2-}$ (all) $-\mathrm{SO}_{4}^{2-}$ (nat). The small methodological difference compared to GSD, where $\mathrm{SO}_{4}^{2-}$ (anth) is estimated from anthropogenic sources alone, has hardly any impact on the results. The anthropogenic sulfate distributions as well as the associated direct radiative forcings are almost identical in GSD and GSDIO.

In addition to the indirect effect, GSDIO takes into account also the radiative forcing due to anthropogenic changes in tropospheric ozone. However, unlike the sulfur cycle, the ozone chemistry is not calculated online with the AOGCM but precalculated with a tropospheric chemistry model coupled to ECHAM4 (Roelofs et al. 1998). Monthly mean estimates based on changing anthropogenic emissions of $\mathrm{NO}, \mathrm{CO}$, and surface concentrations of $\mathrm{CH}_{4}$ are available for preindustrial, presentday (1985), and future (2050) emissions (G.-J. Roelofs 1998, personal communication). According to these simulations, the global annual mean tropospheric ozone concentration has increased from 19.1 Dobson units (DU) for preindustrial emissions to 26.3 DU for presentday emissions and, further, to 31.7 DU in 2050 for anthropogenic emissions prescribed according to scenario IS92a (IPCC 1992). Accordingly, the percentage increase of the $\mathrm{O}_{3}$ column, between 1860 and 1985, is $0.30 \%$ per year (linear), while the respective slope between 1985 and 2050 is predicted to be slightly larger $(0.32 \%$ per year linear). In experiment GSDIO, the timedependent concentrations of ozone and other oxidants like $\mathrm{OH}$ radicals, $\mathrm{H}_{2} \mathrm{O}_{2}$, and $\mathrm{NO}_{3}$ are obtained by linear interpolation between the three data points $(1860,1985$, 2050).

\section{Sulfur simulation}

Figure 2 shows the temporal evolution of the annual mean anthropogenic sulfate burden in the atmosphere as obtained from the GSDIO simulation with anthropogenic emissions prescribed according to Fig. 1. Due to the efficiency of sink processes, that is, dry and wet deposition, the atmospheric lifetime of sulfur species is a few days to a week. While the trend in sulfate burden is directly proportional to the trend in emissions, the interannual variations are reflecting the variability of removal processes as a result of changing weather regimes and local variations in concentrations of oxidants that transform $\mathrm{SO}_{2}$ into sulfate.

In contrast to greenhouse gases like $\mathrm{CO}_{2}$, the historical evolution of atmospheric sulfur is practically un- 


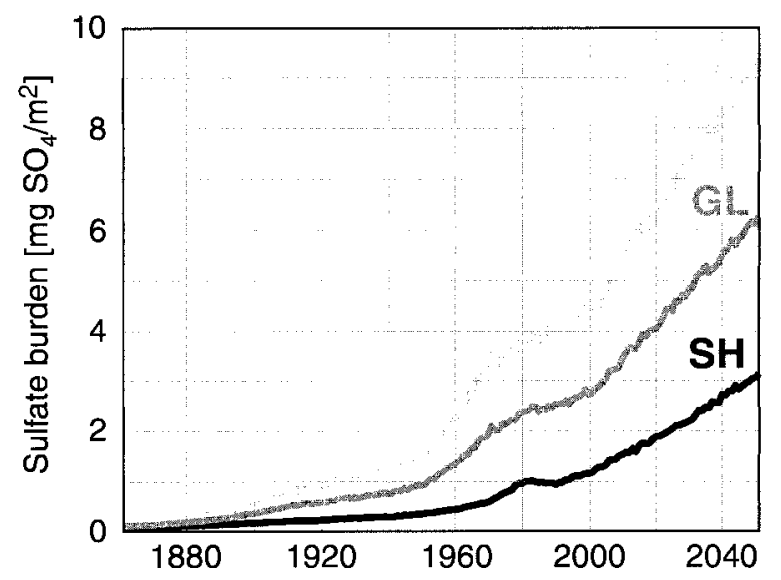

FIG. 2. Temporal evolution of anthropogenic sulfate burden in the Northern Hemisphere (NH), in the Southern Hemisphere (SH), and for the globe (GL), as simulated in the GSDIO experiment. Units are $\mathrm{mg} \mathrm{SO}_{4}^{2-} \mathrm{m}^{-2}$.

known. The only source of information is ice-core data. Measurements of non-sea salt sulfate in ice cores were taken, for example, at sites in Greenland and Antarctica. Figure 3 shows a comparison between the ice-core data at the Dye 3 site in southern Greenland, as reported by Legrand (1995), and the GSDIO simulation in which the sulfur cycle was estimated for both natural and total sulfur emissions, respectively. The observations (Fig. 3a) indicate an increase in deposition of about $50 \mathrm{ng}$ $\mathrm{g}^{-1}$ between the first two decades of the time series (1850-70) and the last ones (1965-85). This is mostly due to fossil fuel-related emissions in North America. Superimposed on the quasi-linear trend are large interannual and interdecadal fluctuations that could be related to the variability in emissions but also to changing weather regimes. In the model simulations (Fig. 3b), the observed trend is reasonably well reproduced but the variability is smaller than observed. In part, this may be a model weakness caused by underestimation of the variability in sulfur emissions. For example, the emissions from noneruptive volcanoes are set constant, the DMS concentration in seawater is allowed to change seasonally but not interannually, and there is no temporal variability in anthropogenic emissions apart from the trend. Different to southern Greenland, there is virtually no trend in deposition at the Antarctic site Dome $\mathrm{C}$, neither in the observations nor in the model simulation (not shown).

Figure 4 shows the spatial patterns of the simulated anthropogenic sulfate burden for the decadal means (a) 1980-90, and (b) 2040-50, and (c) the difference pattern. For the recent period, most of the anthropogenic sulfur is concentrated in the industrialized regions of the Northern Hemisphere (eastern part of the United States, Europe, and East Asia). According to the future scenario (IS92a), the global emissions double between 1990 and 2050 (cf. Fig. 1). The growth is particularly large in the developing countries of both hemispheres,

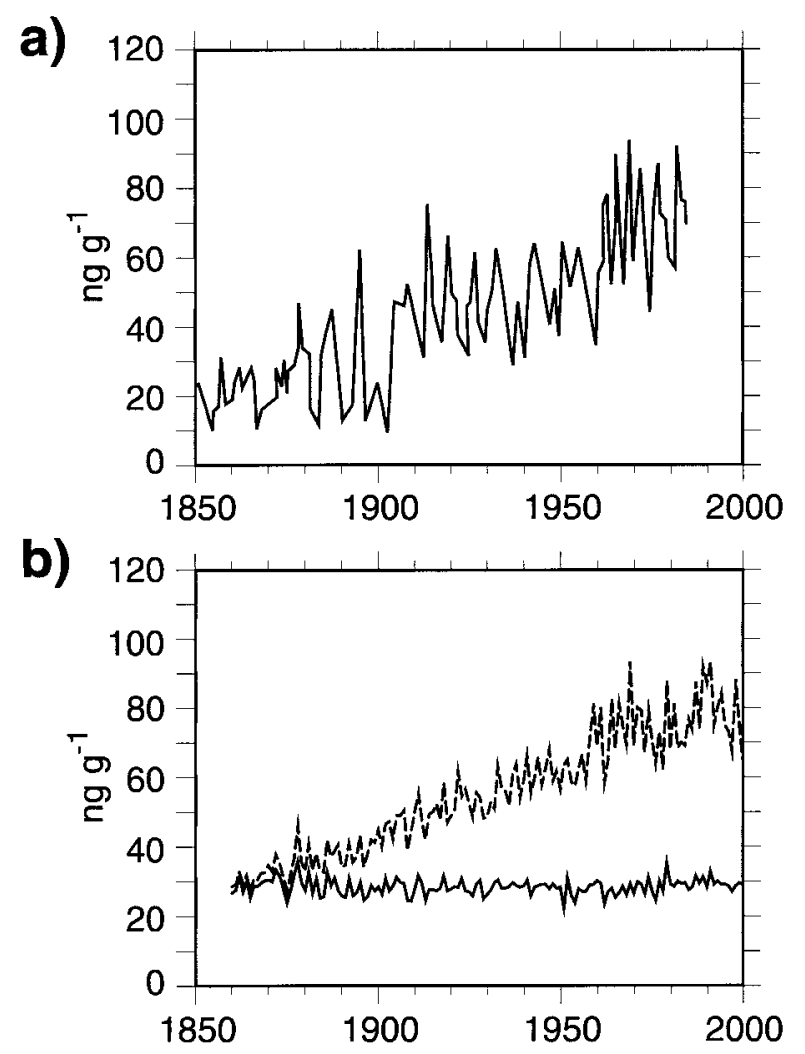

FIG. 3. Temporal evolution of annual sulfate content in snow/ice at the Dye 3 site in southern Greenland $\left(43^{\circ} \mathrm{W}, 65^{\circ} \mathrm{N}\right)$ : (a) Observed (Legrand 1995). (b) GSDIO simulations for the nearest grid point with prescribed natural sulfur emissions only (solid line) and total emissions (natural plus anthropogenic, dashed line).

between about $30^{\circ} \mathrm{N}$ and $30^{\circ} \mathrm{S}$, while the growth is modest in North America and Europe.

Compared to the MOGUNTIA "slow oxidation case" (Langner and Rodhe 1991), which has often been used as input for estimating both the direct aerosol forcing (e.g., Charlson et al. 1991; Kiehl and Briegleb 1993) and the climate response (e.g., Mitchell and Johns 1997; Haywood et al. 1997; Hegerl et al. 1997), the global anthropogenic sulfate burden simulated in GSD and GSDIO is slightly higher (0.38 Tg S for 1980 emissions) than that applied in the studies mentioned above $(0.34$ $\operatorname{Tg} \mathrm{S})$.

\section{Radiative forcing}

As shown in Table 2, the computed radiative forcings for 1990 fall into the range of IPCC (1996) estimates. An exception is the greenhouse gas forcing, which is larger in IPCC because it covers a longer period (17501994) than the model (1860-1990), see appendix. The small discrepancy between the model-calculated GHG forcing shown in Table $2\left(2.11 \mathrm{~W} \mathrm{~m}^{-2}\right)$ and Table A1, line $4\left(2.26 \mathrm{~W} \mathrm{~m}^{-2}\right)$, respectively, is the result of different atmospheric states used in the forcing calculations. While observed distributions of temperature and 

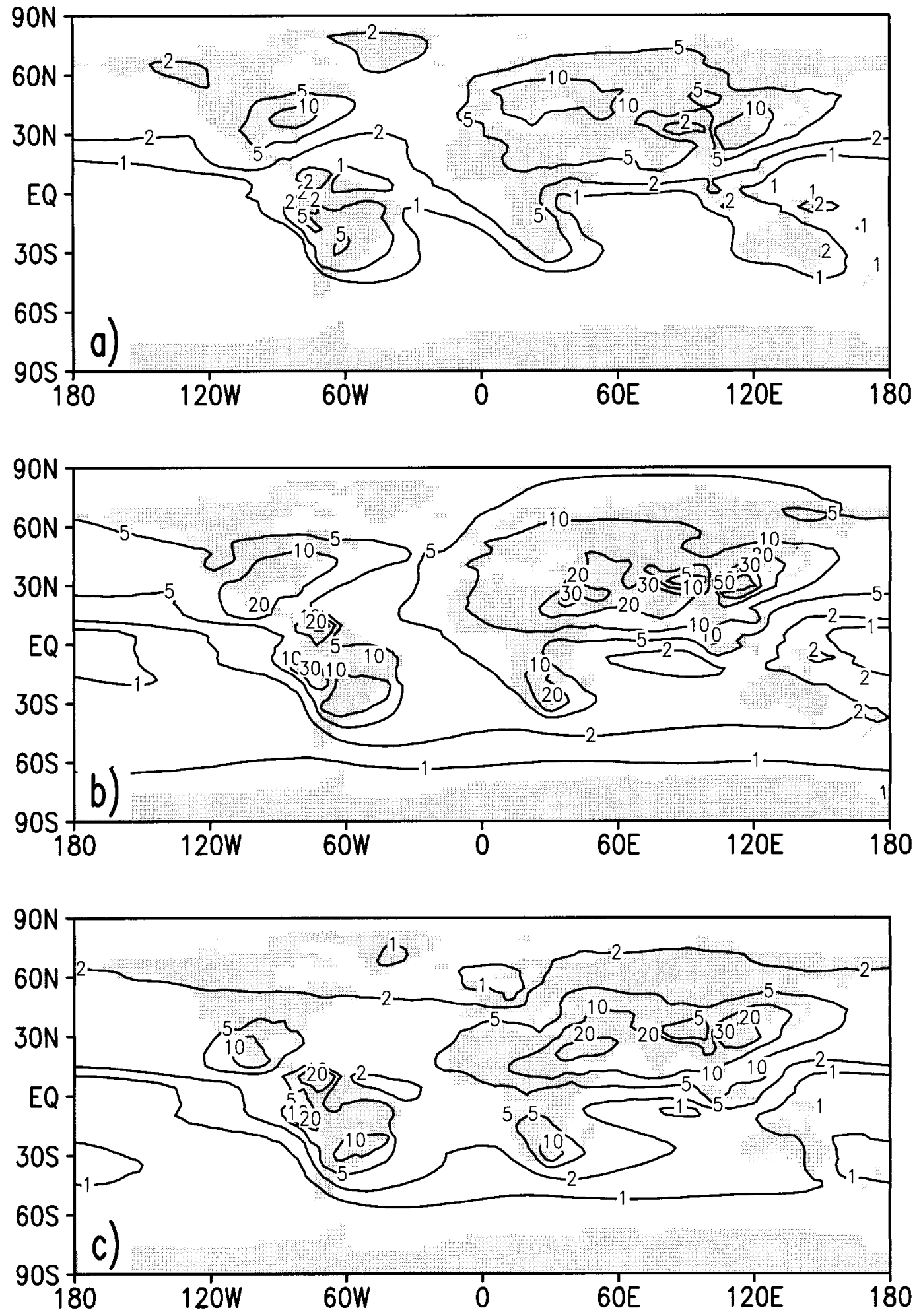

FIG. 4. Decadal mean anthropogenic sulfate burden as simulated in experiment GSDIO. Contour spacing 1, 2, 5, 10, $20,30,50, \ldots \mathrm{mg} \mathrm{SO}_{4}^{2-} \mathrm{m}^{-2}$ : (a) 1980-90, (b) 2040-50, (c) (2040-50) minus (1980-90). 
TABLE 2. Comparison of model-simulated radiative forcings $\left(\mathrm{Wm}^{-2}\right)$ at the top of the tropopause with respective IPCC (1996) estimates.

\begin{tabular}{lcc}
\hline \hline \multicolumn{1}{c}{ Gases or aerosols } & $\begin{array}{c}\text { GSDIO forcing } \\
1860 \rightarrow 1990\end{array}$ & $\begin{array}{c}\text { IPCC '96 forcing } \\
* 1750 \rightarrow 1994\end{array}$ \\
\hline Well-mixed greenhouse gases & & \\
$\left(\mathrm{CO}_{2}, \mathrm{CH}_{4}, \mathrm{~N}_{2} \mathrm{O}, \mathrm{CFC}\right.$ 's $)$ & 2.11 & $2.45^{*}$ \\
Tropospheric ozone & 0.39 & $0.2-0.6$ \\
Direct sulfate aerosol & -0.35 & -0.2 to -0.8 \\
Indirect sulfate aerosol & -0.91 & 0 to -1.5 \\
Total & 1.24 & \\
\hline
\end{tabular}

humidity together with model-derived cloud parameters were applied for calculating the forcings shown in Table A1, the forcings in Table 2 were computed online during the model simulation. The consistency with the IPCC forcing for virtually all of the components illustrates the current state of knowledge, which is rather poor for the indirect aerosol effect, in particular. Moreover, one should note that the direct aerosol effect in Table 2 is due to sulfate alone.

Our estimate of the direct effect is slightly larger than that obtained by Kiehl and Briegleb (1993), - $0.28 \mathrm{~W}$ $\mathrm{m}^{-2}$. The difference is largely due to the neglect of the spatial humidity distribution in our approach (cf. section $3 c)$. Both estimates are significantly smaller than that of Charlson et al. (1991), about $-0.6 \mathrm{~W} \mathrm{~m}^{-2}$, based on a simplified radiative transfer calculation, which has been a standard method employed in climate change experiments. The indirect effect was included so far only by Meehl et al. (1996), who scaled the indirect radiative forcing to give a present-day value of $-0.89 \mathrm{~W} \mathrm{~m}^{-2}$, which happens to be similar to our estimate in the GSDIO experiment. The GSDIO forcing due to tropospheric ozone, $0.39 \mathrm{~W} \mathrm{~m}^{-2}$, is in the middle of the range of current estimates, 0.28-0.62 (Berntsen et al. 1997). To our knowledge, changes in tropospheric ozone were so far neglected in transient climate change experiments.

Figure 5a shows the time evolution of the annual global mean radiative forcings for the three experiments and also for individual components computed in the GSDIO experiment. The tropospheric ozone forcing increases almost linearly throughout the simulation because the ozone concentrations were interpolated linearly between the data points $(1850,1992$, and 2050, see section 3). The indirect $\mathrm{SO}_{4}^{2-}$ effect, until about 1980, increases much faster than the direct effect, but the curves are almost parallel for the rest of the simulation. While the direct effect is determined essentially by the anthropogenic sulfate burden, the indirect (cloud albedo) effect does also depend on the availability of cloud condensation nuclei in the atmosphere, and is larger, for a given change in $\mathrm{SO}_{4}^{2-}$, in pristine air than in polluted air [see Eqs. (2), (3)]. Initially, the indirect effect is able to almost neutralize the greenhouse effect so that the total forcing in GSDIO remains small until about 1970.

Figure $5 \mathrm{~b}$ shows the meridional distribution of zon- a)

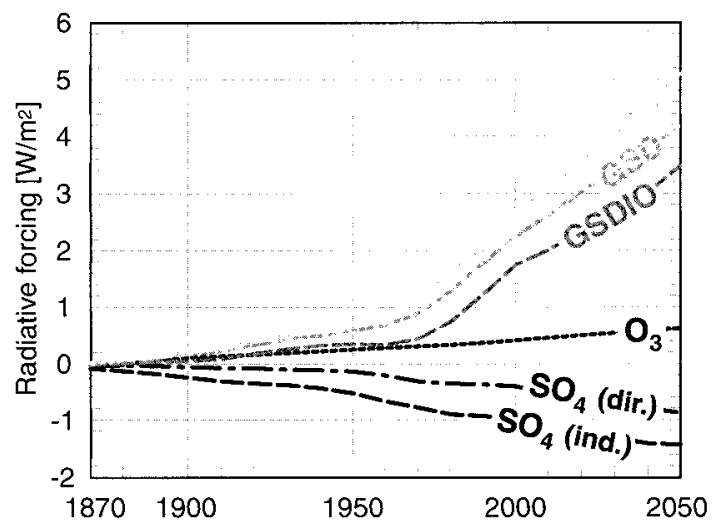

b)

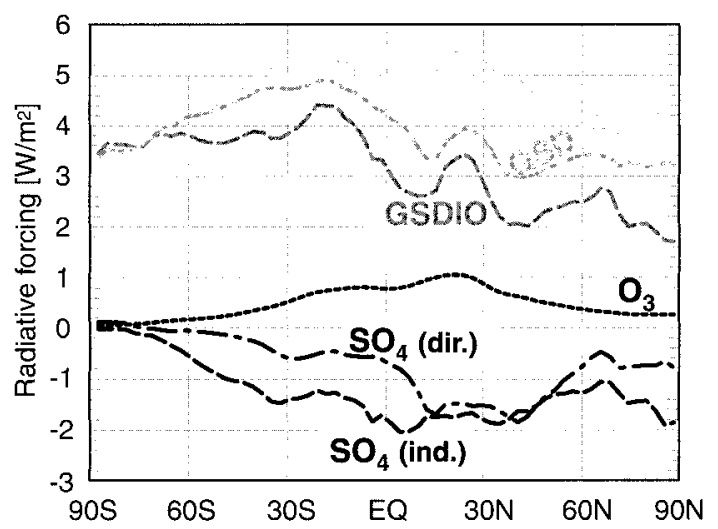

FIG. 5. Annual mean radiative forcings in the three perturbation experiments (cf. Tables 1, 2). Individual forcings due to $\mathrm{O}_{3}$ (troposphere only), $\mathrm{SO}_{4}^{2-}$ (direct), and $\mathrm{SO}_{4}^{2-}$ (indirect) were computed in GSDIO. (a) Temporal evolution of global means. (b) Latitudinal profiles of zonal means for the period 1860 to (2040-50)

ally averaged radiative forcings for the period 1860 to 2040-50. In all experiments, the total radiative forcing is larger in the Southern Hemisphere than in the Northern Hemisphere. This is most pronounced in GSDIO, which includes all of the forcings shown in this figure. For the same reason discussed earlier, the direct and indirect $\mathrm{SO}_{4}^{2-}$ effects are more similar to each other in the "polluted" Northern Hemisphere than in the relatively cleaner Southern Hemisphere. Although the mean residence time of tropospheric ozone is about 4 weeks or less, and the anthropogenic source regions are mainly in the Northern Hemisphere, there is little hemispheric asymmetry in ozone forcing, and the profile is similar in shape to that of the well-mixed greenhouse gases. This can be related to the release of ozone precursor species through biomass burning, which is very important in the Southern Hemisphere as well.

The total GSDIO forcing patterns for two decades, together with the difference, are shown in Fig. 6. The widespread areas with negative total forcing up to the decade 1980-90 (a) are predominantly caused by the indirect $\mathrm{SO}_{4}^{2-}$ effect. This is particularly evident in oce- 


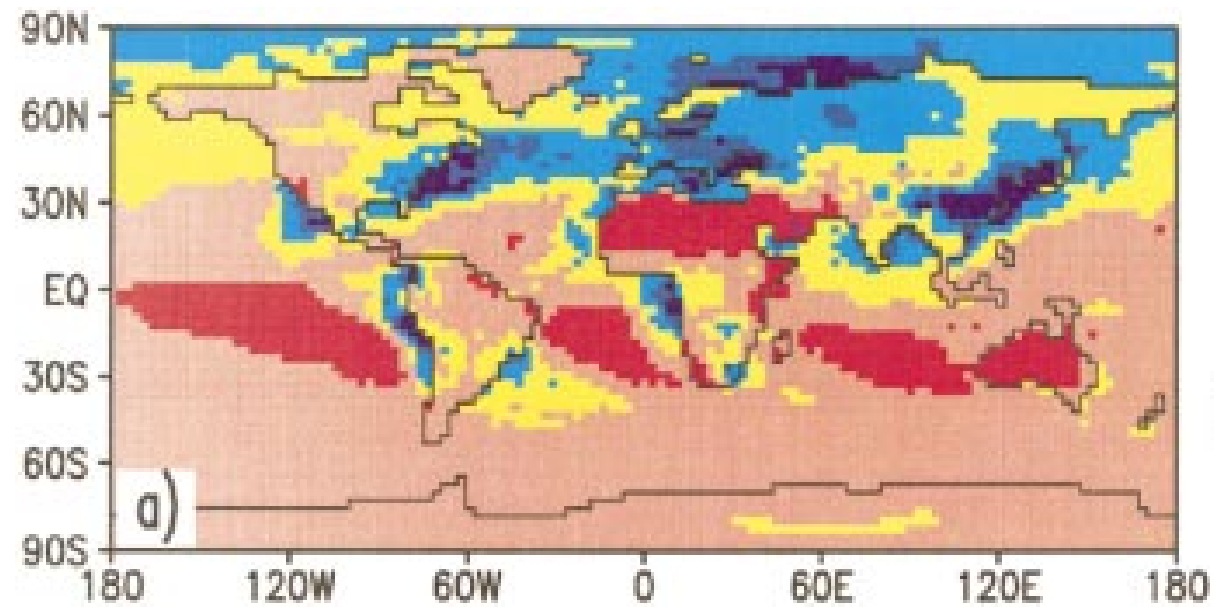

$[W / m * m]$
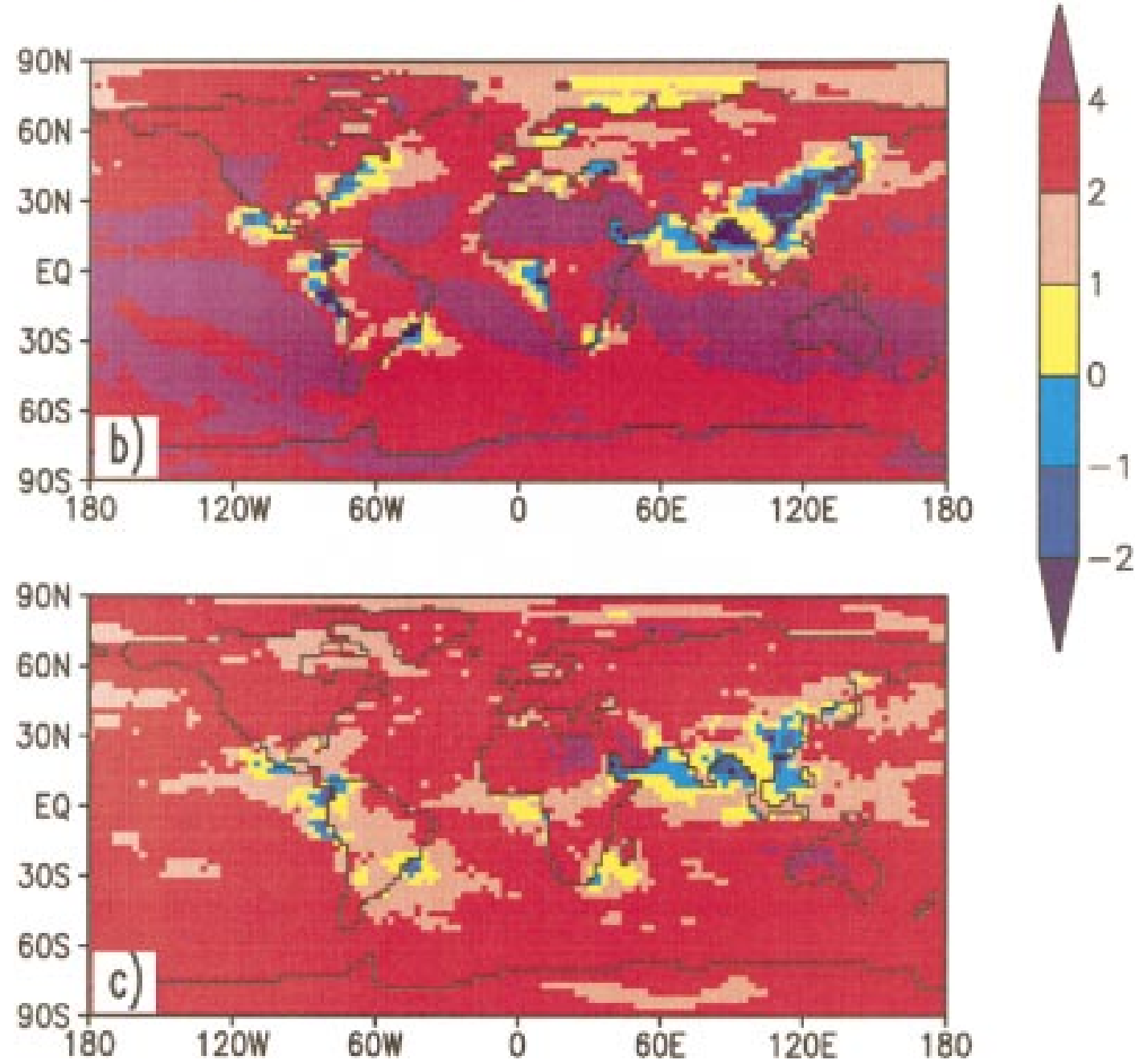

FIG. 6. Decadal mean total radiative forcing in experiment GSDIO. Units are $\mathrm{W} \mathrm{m}^{-2}$ : (a) 1980-90, (b) 2040-50, (c) (2040-50) minus (1980-90). 
TABLE 3. Heat fluxes in CTL and differences between decadal means in the perturbation experiments (2040-50) and the 300-yr mean CTL fluxes. In brackets: GHG change (2000-10), corresponding to roughly the same temperature change as in GSDIO for the decade $2040-50$. Downward (upward) fluxes are positive (negative). Units are $\mathrm{W} \mathrm{m}^{-2}$.

\begin{tabular}{|c|c|c|c|c|}
\hline & CTL & GHG - CTL & GSD - CTL & GSDIO - CTL \\
\hline \multicolumn{5}{|l|}{ Top of atmosphere } \\
\hline Shortwave (clear sky) & +287.6 & $+1.52(+1.03)$ & -0.45 & -0.71 \\
\hline Long wave (clear sky) & -264.4 & $+0.62(+0.41)$ & +1.80 & +3.11 \\
\hline$=$ surface emission & -398.1 & $-12.51(-7.42)$ & -9.71 & -7.61 \\
\hline + clear-sky greenhouse effect & +133.7 & $+13.13(+7.83)$ & +11.51 & +10.72 \\
\hline Shortwave cloud forcing & -49.8 & $-1.38(-0.65)$ & -0.17 & -1.14 \\
\hline Longwave cloud forcing & +28.9 & $+0.63(+0.30)$ & +0.06 & -0.28 \\
\hline \multirow{2}{*}{\multicolumn{5}{|c|}{ Atmosphere }} \\
\hline & & & & \\
\hline Shortwave (clear sky) & +72.0 & $+3.39(+1.86)$ & +3.73 & +3.77 \\
\hline Longwave (clear sky) & -190.9 & $-6.31(-3.57)$ & -4.64 & -3.52 \\
\hline Shortwave cloud forcing & +17.1 & $-0.02(-0.09)$ & -0.22 & -0.35 \\
\hline Longwave cloud forcing & +8.1 & $+2.17(+1.24)$ & +1.48 & +1.22 \\
\hline Net atmospheric radiation & -93.7 & $-0.77(-0.56)$ & +0.36 & +1.12 \\
\hline \multicolumn{5}{|l|}{ Surface } \\
\hline Sensible heat flux & -11.9 & $+0.66(+0.42)$ & +0.83 & +0.79 \\
\hline Latent heat flux & -81.9 & $-1.37(-1.00)$ & -0.42 & +0.39 \\
\hline Shortwave (clear sky) & +215.6 & $-1.87(-0.82)$ & -4.18 & -4.47 \\
\hline Longwave (clear sky) & -73.5 & $+6.93(+3.97)$ & +6.44 & +6.63 \\
\hline Shortwave cloud forcing & -66.9 & $-1.36(-0.56)$ & +0.05 & -0.79 \\
\hline Longwave cloud forcing & +20.8 & $-1.55(-0.94)$ & -1.43 & -1.51 \\
\hline Net surface radiation & +96.0 & $+2.16(+1.65)$ & +0.88 & -0.14 \\
\hline Net surface heat flux & +2.2 & $+1.45(+1.06)$ & +1.29 & +1.05 \\
\hline
\end{tabular}

anic regions downwind of anthropogenic sources. For the period 1860 to $2040-50$ (b), the effect of the greenhouse gases is clearly dominating, and negative forcings can be found only in regions with extremely high sulfate burdens like eastern Asia (cf. Fig. 4b) and in a few coastal regions in the vicinity of sources where lowlevel clouds are abundant. The trend in radiative forcing from present to future (Fig. 6c) is predominantly governed by the increase in greenhouse gases, and modulated by the increase in aerosols, especially at lower latitudes where the increase in sulfate burden is larger than at higher latitudes (cf. Fig. 4c).

The forcing pattern for 2040-50 differs from that shown in previous studies (e.g., Mitchell and Johns 1997) where a negative total forcing is simulated over large parts of Asia. In these studies, the total aerosol forcing included a relatively large direct effect, compared to our estimate, while the indirect effect was neglected. The direct effect is particularly effective over regions with high sulfate burden, that is, over the continental source regions. In GSDIO, which has a similar global mean forcing as the SUL $\left(\mathrm{CO}_{2}\right.$ plus sulfate) experiment of Mitchell and Johns, the direct effect is smaller while the largest contribution to the total aerosol forcing is from the indirect effect, which is more effective over sea than over land. Also, the tropospheric ozone forcing in GSDIO tends to counteract the aerosol cooling somewhat more over land than over sea (not shown).

\section{Climate response}

\section{a. Changes in global heat budget}

While the radiative forcing of greenhouse gases is primarily "felt" by the atmosphere, the radiative forcing of nonabsorbing aerosols like sulfate is felt at the surface. In the perturbation experiments GHG, GSD, and GSDIO, the changes in heat budget, which are shown in Table 3, are the result of both radiative forcings and climate feedbacks.

In GHG, the increase in absorbed shortwave clearsky radiation at the top of the atmosphere (TOA) is related to a decrease in clear-sky planetary albedo due to melting snow and sea ice. In GSD and GSDIO, on the other hand, the clear-sky albedo increases due to rising concentrations of tropospheric aerosols. This direct aerosol effect is able to efficiently counteract the former effect so that there is globally less absorption than in GHG or CTL.

The changes in TOA clear-sky longwave radiation depend on changes in temperature and absorbing gases in the atmosphere. The latter has a direct and an indirect component. The direct one is due to the radiative forcing through prescribed changes of $\mathrm{CO}_{2}$ and other greenhouse gases. The indirect effect is related to the water vapor feedback. In GHG, the changes in TOA longwave clear-sky radiation are positive, but rather small, because the increase in surface emission, as a result of surface warming, is almost balanced by the larger clear-sky greenhouse effect in the warmer and therefore moister atmosphere. Here, the greenhouse effect of the atmosphere is defined as the difference between TOA longwave radiation and surface emission (Raval and Ramanathan 1989). In GSD and GSDIO, such a balance no longer occurs, and less clear-sky longwave radiation is emitted to space than in GHG. The main reason for this change is aerosol cooling of the surface, which leads to a reduction of surface emission. On the other hand, 
relative to GHG, the water vapor greenhouse effect is reduced in the colder and drier atmosphere (note that the greenhouse gas forcing is almost identical in the perturbation experiments), but this water vapor impact, for a given change in temperature, is clearly smaller than the highly nonlinear surface emission effect according to the Stefan-Boltzmann law.

Changes in cloud radiative forcing, that is, cloud feedbacks, are related to changes in cloud amount and cloud water as a result of changing temperatures. Shortwave cloud feedback also includes changes in clear-sky albedo. In GHG, the shortwave cloud feedback is negative because the clouds are becoming optically thicker in a warmer atmosphere. For the same reason, the longwave cloud feedback is positive. Although these feedbacks operate in GSD and GSDIO as well, they are modified by differences in the changes of temperature, snow, and sea ice, and also by the indirect cloud albedo effect (GSDIO). However, in all experiments, the net cloud feedback is negative.

Changes in aerosol concentrations have a noticeable influence on the surface heat budget. In GHG, the sensible heat flux is reduced compared to CTL, leading to a surface warming, while the increase in latent heat flux contributes to a surface cooling. The impact of increasing aerosols on the latent heat flux is to reduce the surface cooling (GSD) or even produce a surface warming when the indirect effect is included in addition (GSDIO). These effects are primarily due to reductions in clear-sky shortwave radiation at the surface, which are much larger in GSD and GSDIO than in GHG. As a result, the net radiation change at the surface $(2.16 \mathrm{~W}$ $\mathrm{m}^{-2}$ in $\mathrm{GHG}$ ) is reduced to $0.88 \mathrm{~W} \mathrm{~m}^{-2}$ in GSD and becomes even negative in GSDIO. The changes in GHG have the same sign as the "normal" flux distribution in CTL: while the atmosphere is cooled radiatively, the surface is warmed and the turbulent flux anomalies are directed upward. In GSDIO, compared to CTL, the atmosphere is warmed radiatively while the surface is cooled so that the anomalous transfer of heat (both sensible and latent heat flux) is downward from the atmosphere to the surface.

A similar mechanism was discussed by Boer (1993) in $\mathrm{CO}_{2}$ doubling experiments with and without cloud optical depth feedback, respectively. Without this feedback, the surface is warmed radiatively by changes in both longwave and shortwave radiation and cooled by increased latent heat flux. Including this feedback, less solar radiation reaches the surface, because clouds are optically thicker in the warmer atmosphere, so that the increase in latent heat flux and precipitation is damped. In GSDIO, due to changes in both cloud optical properties and aerosol concentrations, the latent heat flux even decreases with increasing temperature. This somewhat counterintuitive result will be discussed in more detail below.
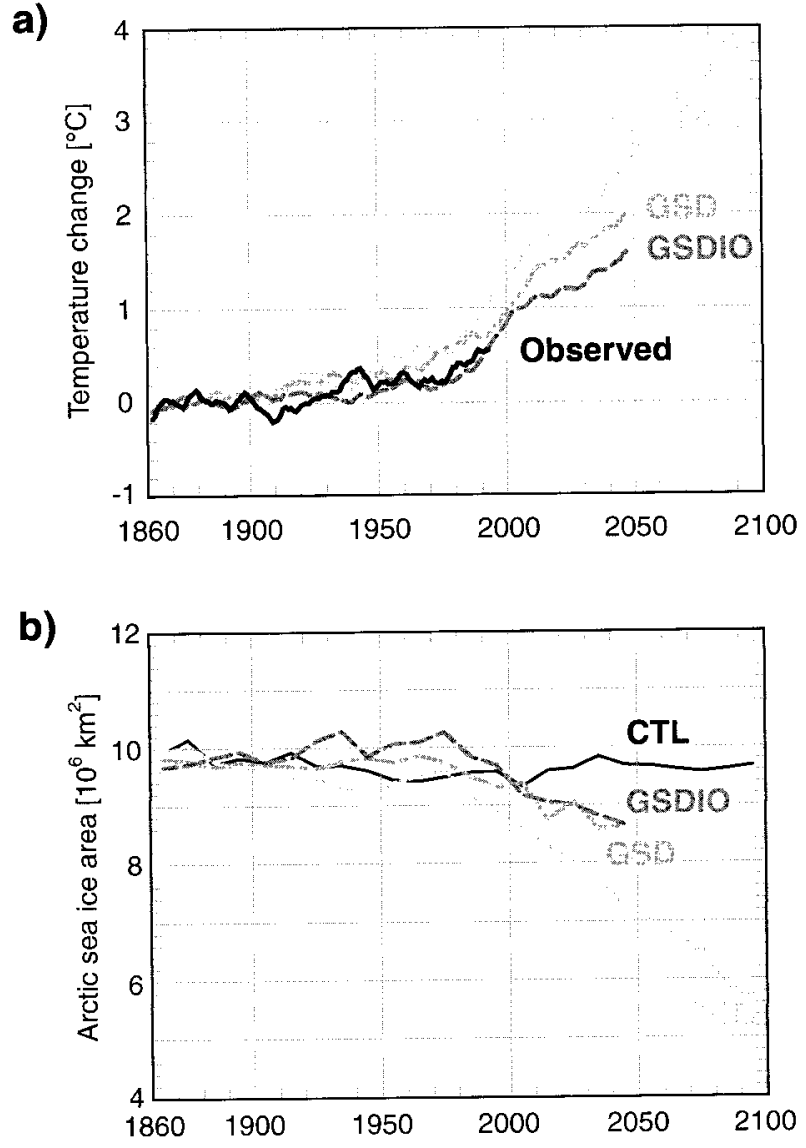

FIG. 7. (a) Temporal evolution of annual global mean surface air temperature compared to the CTL mean (for the simulations) and compared to the observational mean (1860-1900) for the observations (solid line; D. Parker 1998, personal communication). Smoothing by 5 -yr running means. (b) Temporal evolution of decadal mean Arctic sea-ice area.

\section{b. Temporal evolution of temperature and sea ice}

As an example of the evolution of climate change, Fig. 7a shows changes in global mean surface air temperature with respect to CTL. Apart from interdecadal variations, the trends in the three perturbation experiments follow those in radiative forcing (cf. Fig. 5a). Due to the negative aerosol radiative forcing, the decadal warming trend between 2000 and 2050 is reduced from $0.28 \mathrm{~K}$ in GHG to $0.24 \mathrm{~K}$ in GSD and, further, to $0.20 \mathrm{~K}$ in GSDIO. In the period 1860-1990, the warming in GHG and GSD evolves too fast compared to the observational record, while the GSDIO trend is in better agreement with the observations. The same conclusion was drawn by Johns et al. (1997), who compared a set of experiments (GHG, SUL) in which similar global mean forcings, but different mechanisms, were applied as in our experiments (GHG, GSDIO).

Global warming is associated with a decrease of sea ice. While sea ice melting is modest around Antarctica (not shown), it becomes significant in the Arctic. Figure 
$7 \mathrm{~b}$ shows the temporal evolution of annual mean Arctic sea ice area in CTL and in the three perturbation experiments. Compared to observations (Gloersen et al. 1992; not shown) the annual mean sea ice in CTL is underestimated by about $10 \%$ in both hemispheres. In GHG, until about 1970, the evolution in sea ice is not significantly different from that in CTL. Later, from the 1970 s to the 2090s the Arctic sea ice area decreases by about $40 \%$. In GSDIO, a slow increase until the 1970 s is calculated while the onset of the melting is in the 1970s, as in GHG, and the rate of decay until the 2040s is just slightly smaller than that found in GHG. This behavior is closely related to the evolution in total radiative forcing in the Northern Hemisphere. In GHG, the forcing becomes large from about 1970 onward, while in GSDIO, during the first part of the simulation, it is negative over the Arctic and other parts of the Northern Hemisphere (cf. Fig. 6a). Later, between about 1980 and 2050, the relative contribution of the aerosols becomes smaller so that the change in total forcing is positive in most parts of the Northern Hemisphere (cf. Fig. 6c).

\section{c. Temperature change patterns}

The patterns of annual temperature change for the period 2030-50, compared to CTL, are shown in Fig. 8. In all experiments, independent of type and strength of forcing and consistent with many previous studies (as summarized in IPCC 1996), the warming is larger over land than over ocean. Moreover, there is little warming in regions where the effective heat capacity of the ocean is large. This is caused by efficient vertical mixing in areas like the North Atlantic, and particularly in the Southern Ocean, around Antarctica, where even a slight cooling may occur (e.g., Manabe et al. 1991). The inclusion of aerosols $(b, c)$ leads to smaller warming. Although the total radiative forcing is negative in some regions (cf. Fig. 6b), areas of cooling are confined to the Southern Ocean where the trend is small and the natural variability is large. Temperature differences between the perturbation experiments are shown in Fig. 9. Similar to previous experiments with and without aerosols (e.g., Mitchell et al. 1995a; Hegerl et al. 1997; Mitchell and Johns 1997), widespread aerosol cooling occurs in the Northern Hemisphere where the main sources of the anthropogenic sulfate aerosols are located; however, the industrial regions do not stand out. On the other hand, the aerosol cooling is relatively large in remote areas like parts of the Arctic. In the Southern Hemisphere, a direct aerosol effect on temperature change is not detectable (Fig. 9a), and the extended areas of warm anomalies are indications of large natural variability. However, when the indirect effect is included (Fig. 9b) the cooling, compared to GHG, spreads over large parts of the Southern Hemisphere.

The meridional distribution of changes in zonal-mean surface air temperature is shown in Fig. 10. Although an amplification of the warming at high northern latitudes is evident in all experiments, it is considerably reduced through aerosol effects. In the Southern Hemisphere, the relatively large differences between GSDIO and GSD are not inconsistent with the respective forcing patterns (cf. Fig. 5b). However, unlike the global means, a close relationship between forcing and response can no longer be expected for regional scales. The influence of internal atmospheric processes like energy transports and feedbacks becomes important already for the annual zonal-mean temperature distribution, which obviously cannot be aligned with the associated forcing pattern (cf. Figs. 5b, 10). Another process that is able to virtually neutralize the radiative forcing in transient response experiments is efficient ocean mixing around Antarctica.

Figure 11 shows annual zonal-mean temperature changes, relative to CTL, as a function of latitude and height. All experiments produce a maximum warming in the upper-tropical troposphere, a relatively warm Arctic as well, a pronounced delay of the warming near $60^{\circ} \mathrm{S}$, and a cooling in the stratosphere. These are features, which are typical in transient $\mathrm{CO}_{2}$ warming experiments, with or without sulfate aerosols included (e.g., Mitchell and Johns 1997). The impact of the aerosols is to reduce the greenhouse warming in much of the troposphere. This is demonstrated in Fig. 12, which shows the temperature differences between the perturbation experiments. The impact of the aerosols in (a) GSD and (b) GSDIO is larger in the Northern than in the Southern Hemisphere, with local maxima in the Arctic, close to the surface, and in the upper-tropical troposphere. The weak stratospheric warming is more likely a response to tropospheric cooling than a direct radiative impact of the aerosols. The cooling in GSDIO with respect to GSD (Fig. 12c) is fairly uniform.

\section{d. Zonal wind and sea level pressure}

According to Fig. 13, there is a significant increase in mean westerly wind in the upper troposphere and lower stratosphere (areas in which the changes are not significant at the $95 \%$ confidence level are indicated by shading). The increase of the westerlies aloft is related to the increased temperature gradient at these heights due to low-latitude warming and high-latitude cooling (cf. Fig. 11). Around $60^{\circ} \mathrm{N}$ and $60^{\circ} \mathrm{S}$, the westerly wind anomaly tends to penetrate down to the surface. These westerly anomalies together with anomalous easterly components centered at $30^{\circ} \mathrm{S}$ and $45^{\circ} \mathrm{N}$, respectively, are indicative of a poleward shift of the midlatitude circulation regimes. While the Southern Hemisphere response is very robust, the Northern Hemisphere response is slightly weaker in GSD and GSDIO compared to GHG. It seems that the zonal wind response is predominantly governed by the amount of warming while the changes in its meridional distribution (cf. Figs. 11 and 12) are less important. 

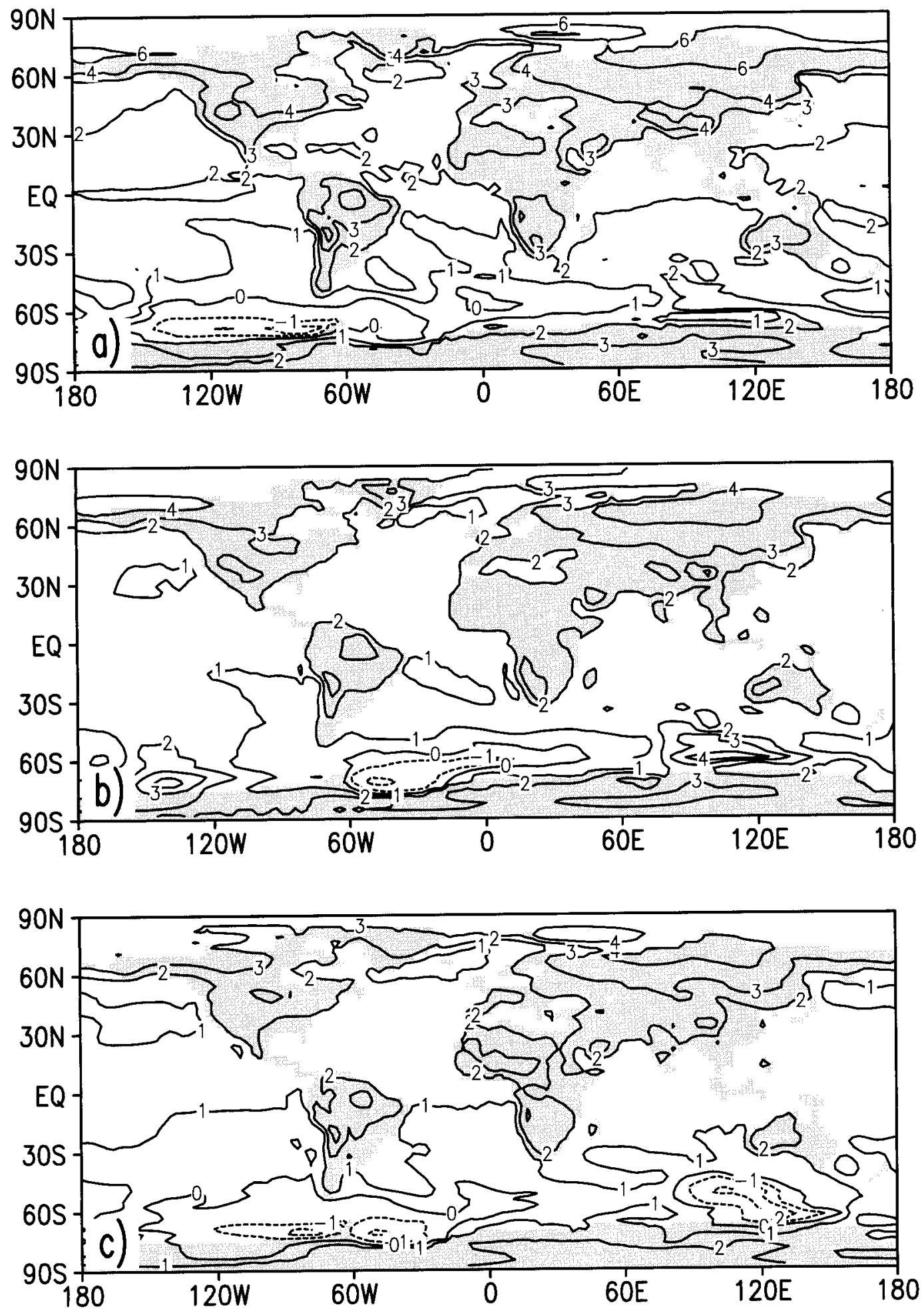

FIG. 8. Changes in annual mean surface air temperature for the period (2030-50) compared to the CTL mean. Contour spacing $\pm 0,1,2,4,6, \ldots{ }^{\circ} \mathrm{C}$ : (a) GHG - CTL, (b) GSD - CTL, (c) GSDIO - CTL. 

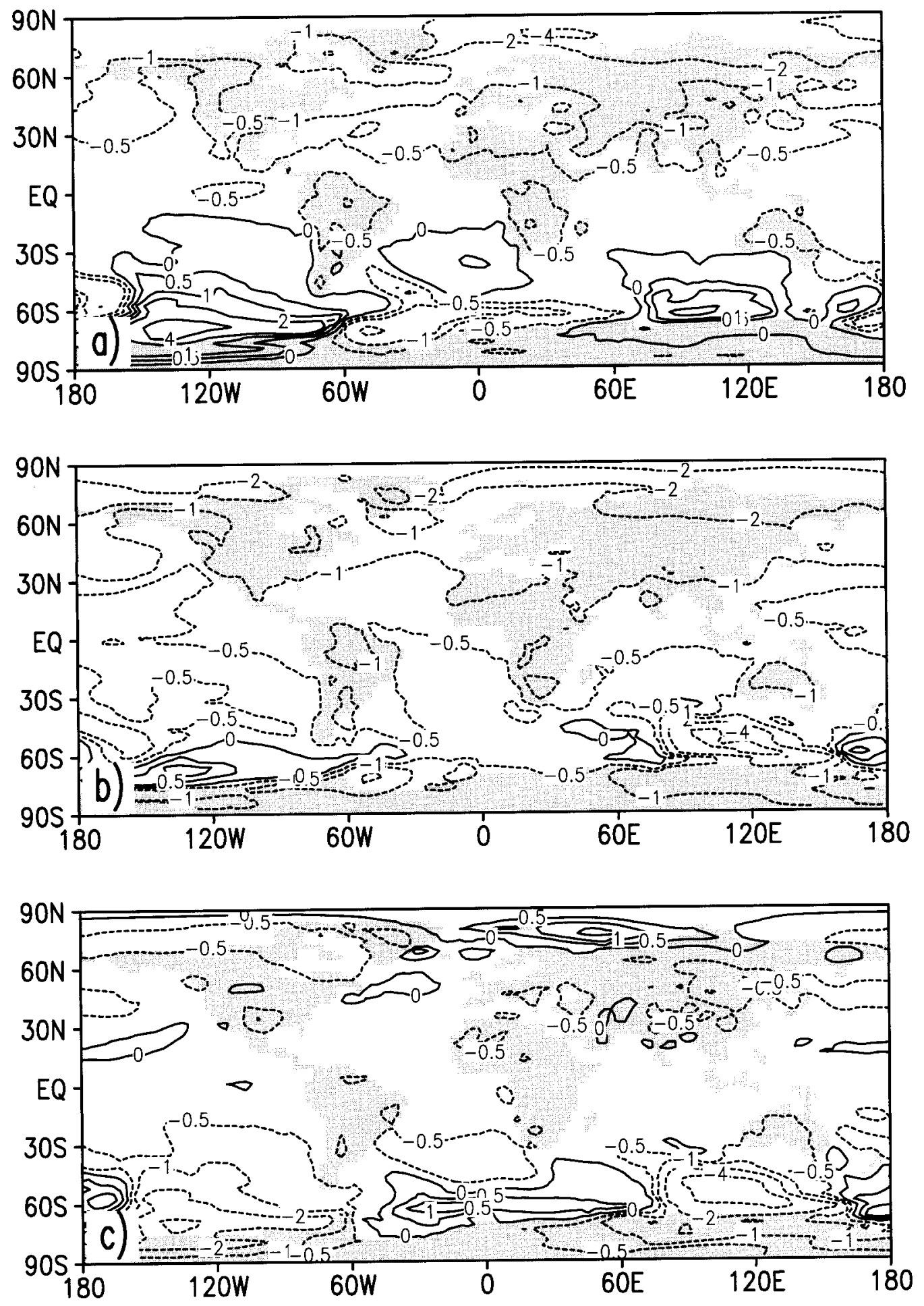

FIG. 9. As Fig. 8 but changes between experiments for the period (2030-50). Contour spacing $\pm 0,0.5,1,2,4,6$, . ${ }^{\circ} \mathrm{C}$. (a) GSD - GHG (response to direct aerosol forcing). (b) GSDIO - GHG (response to direct and indirect effects, and tropospheric ozone). (c) GSDIO - GSD (response to the indirect effect, and tropospheric ozone). 


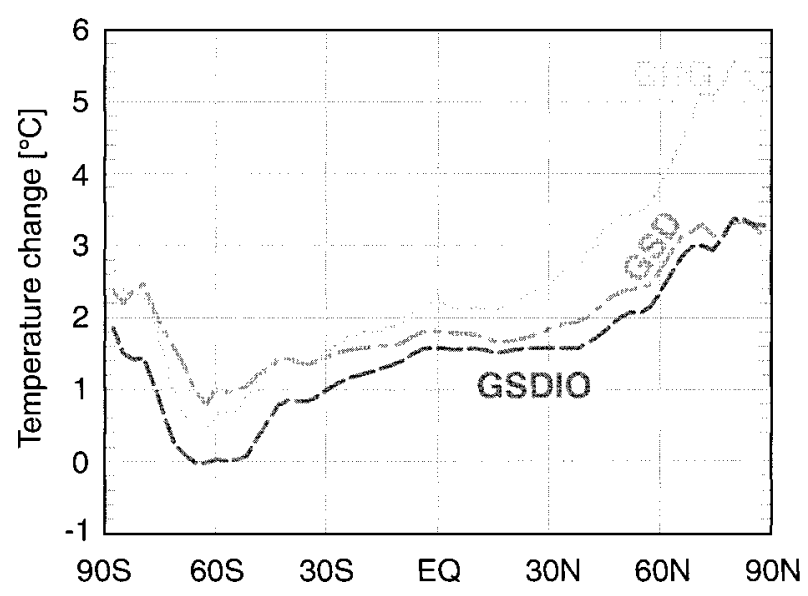

FIG. 10. Latitudinal profiles of changes in annual zonal-mean surface air temperature for the period (2030-50) compared to the CTL mean.

The changes in the spatial pattern of annual mean sea level pressure (SLP) are shown in Fig. 14. In all experiments, the pressure over the polar regions is reduced. Moreover, in accord with the zonal wind response, a southward displacement of the climatological pressure patterns in the Southern Hemisphere leads to a strengthening of the geostrophic westerlies around $60^{\circ} \mathrm{S}$. In the Northern Hemisphere, a poleward shift of the SLP patterns is also detectable, but it is less pronounced than in the Southern Hemisphere. In GHG and GSDIO, the shift is evident in the northeastern Atlantic, in particular, so that the geostrophic westerlies in this region are enhanced. The areas of significant change, at the $95 \%$ level, are much larger than could be expected by chance alone (5\%). In GSD and GSDIO, the SLP changes are statistically significant in 50\%-60\% of the area (not shown), while in GHG the area of significant change is even larger (almost $80 \%$ of the globe). Similar to the zonal wind response, the aerosol effect on SLP, in the Southern Hemisphere, is rather small. In the Northern Hemisphere, due to the larger aerosol cooling, the differences between the experiments are more pronounced. Similar to the zonal wind, the effect of aerosols on the SLP distribution is primarily a damping of the GHG response through widespread relative cooling in the Northern Hemisphere.

\section{e. Water fluxes, soil moisture, and diurnal temperature range}

In the discussion of the heat budget (cf. Table 3 ) it was noted that aerosols modify the latent heat flux at the surface in a way that it becomes negative, compared to CTL, when both the direct and indirect effects are included (GSDIO). This can also be seen in Table 4, which shows the response of the global hydrological cycle. All of the hydrological changes in Table 4 are percentage changes divided by the corresponding changes in surface air temperature, which is shown in addition. In $\mathrm{GHG}$, the normalized changes in global precipitation and evaporation are about $0.7 \%{ }^{\circ} \mathrm{C}^{-1}$. As indicated by the numbers in brackets, the normalized change can be regarded as typical for the GHG simulation. In GSD, the change is smaller, but still positive, while a weakening of the global hydrological cycle is simulated in GSDIO. Over sea, the GSDIO changes are negative for both precipitation and evaporation. However, the net water flux from the ocean increases because the decrease in precipitation is larger than the decrease in evaporation. Consequently, more water than in CTL can be transported to the continents so that the hydrological cycle over land becomes more active. This applies to all experiments. Compared to GHG, the aerosol damping of the hydrological cycle is larger than could be expected from the respective change in temperature alone. It is due, additionally, to a changed distribution of net radiative fluxes between the atmosphere and the surface (cf. Table 3).

Latitudinal profiles of changes in annual mean precipitation are shown in Fig. 15. Over land (a), precipitation increases in all experiments except in the southern part of South America $\left(40^{\circ} \mathrm{S}-50^{\circ} \mathrm{S}\right)$ where the decrease is forced dynamically (cf. Fig. 14). Due to additional aerosol forcing, the precipitation increase is smaller in GSD and GSDIO than in GHG. The associated changes over sea (b) show a different latitudinal profile than over land. Precipitation is enhanced in a narrow band along the equator, and poleward of about $45^{\circ}$, while there is less precipitation than in CTL in the subtropics. In all experiments, the subtropical decrease is on average larger than the increase at other latitudes so that the mean precipitation change over sea is always negative (cf. Table 4). To a large extent, the patterns are forced dynamically. At lower latitudes, changes in evaporation ( $\Delta \mathrm{E}$, not shown) are much smaller than those in precipitation $(\Delta \mathrm{P})$ so that the equatorial maximum in Fig. 15b is due to enhanced moisture convergence, $\Delta(\mathrm{P}-\mathrm{E})>0$, while the opposite holds for adjacent areas where moisture divergence prevails as a result of compensating subsidence. The impact of aerosols is evident at low latitudes, in particular, but also throughout the extratropical Northern Hemisphere. The zonal averages over all land and sea areas are similar to those over sea (Fig. 15c).

The spatial distributions of annual mean precipitation changes are shown in Fig. 16. The large-scale patterns are very similar in the three experiments. As in several other models (e.g., Meehl and Washington 1996), the El Niño-like response in the tropical Pacific, over South America and the tropical Atlantic, is related to an El Niño-like change in mean SST pattern in the tropical Pacific, with stronger warming in the eastern part than in the western part. As shown by Timmermann et al. (1999), this change in mean SST can be regarded as independent of the changes in ENSO variability in our model. The drying over northeastern Brazil and the trop- 

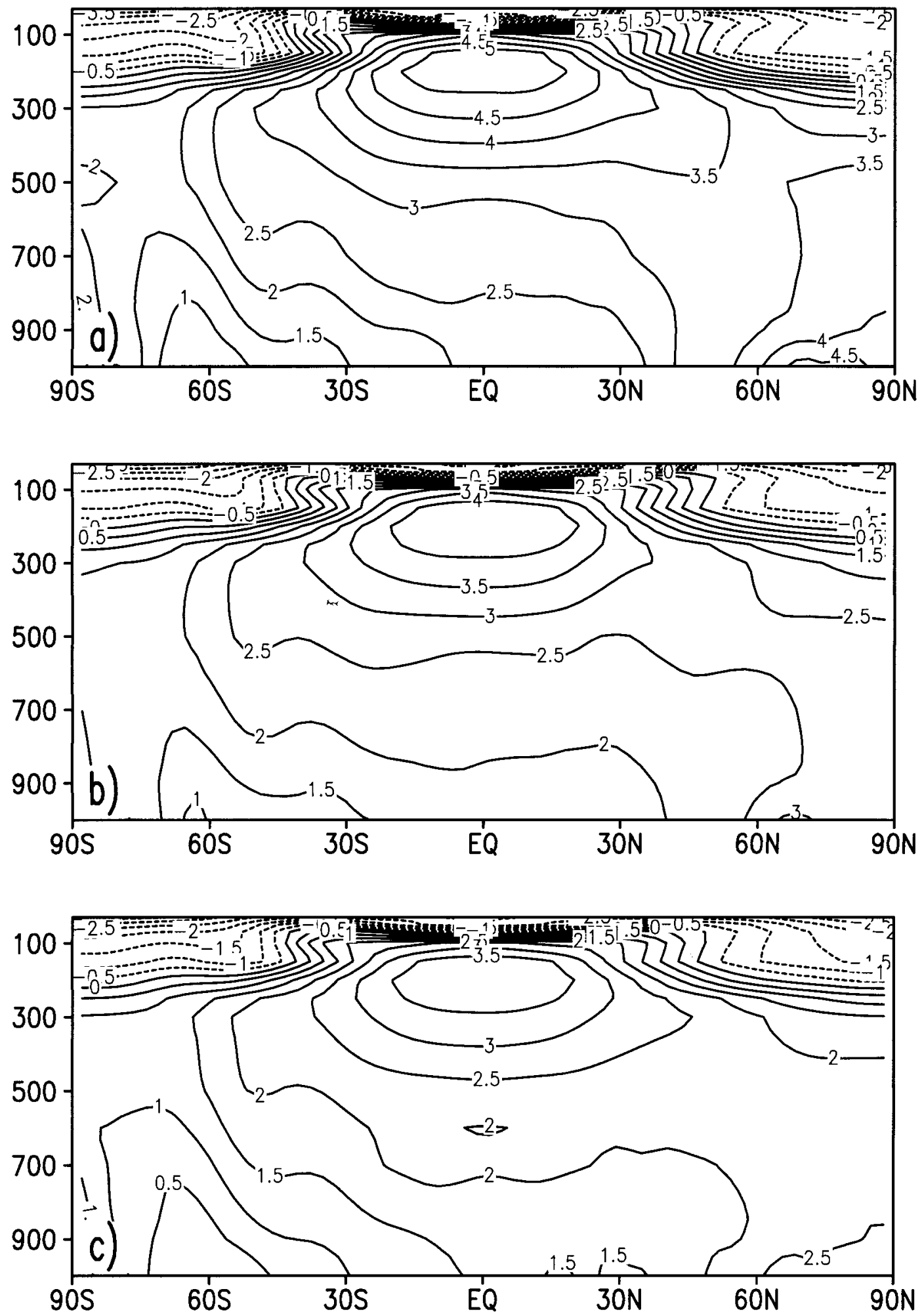

FIG. 11. Latitude-height cross sections of changes in annual zonal-mean temperature for the period (2030-50) compared to the CTL mean. The height coordinate is pressure in $\mathrm{hPa}$. Contour spacing $0.5^{\circ} \mathrm{C}$ : (a) GHG $-\mathrm{CTL}$, (b) GSD $-\mathrm{CTL}$, (c) GSDIO - CTL. 

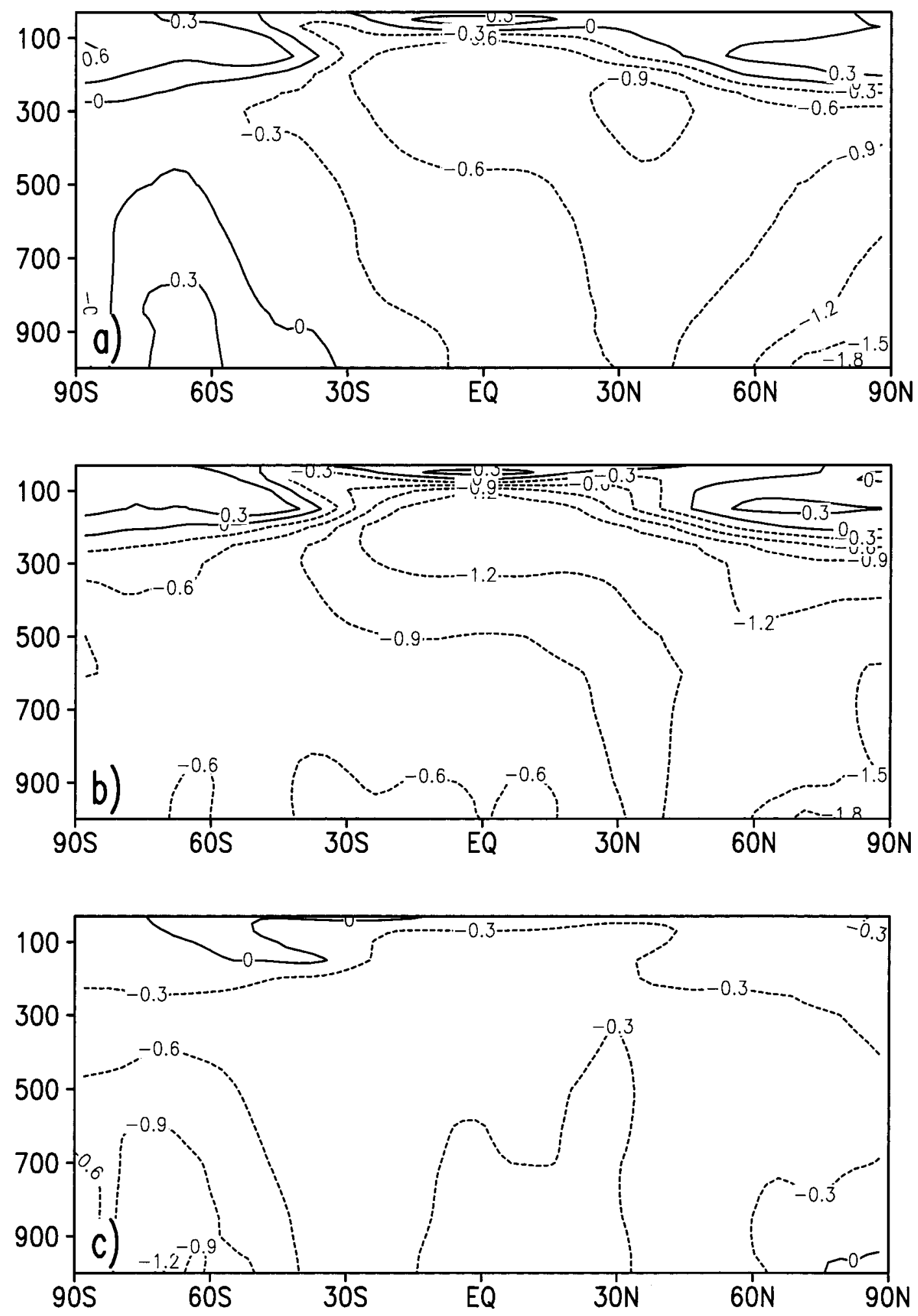

FIG. 12. As Fig. 11 but changes between experiments (2030-50). Contour spacing $0.3^{\circ} \mathrm{C}$. (a) GSD - GHG (response to direct aerosol forcing). (b) GSDIO - GHG (response to direct and indirect effects, and tropospheric ozone). (c) GSDIO - GSD (response to the indirect effect, and tropospheric ozone). 

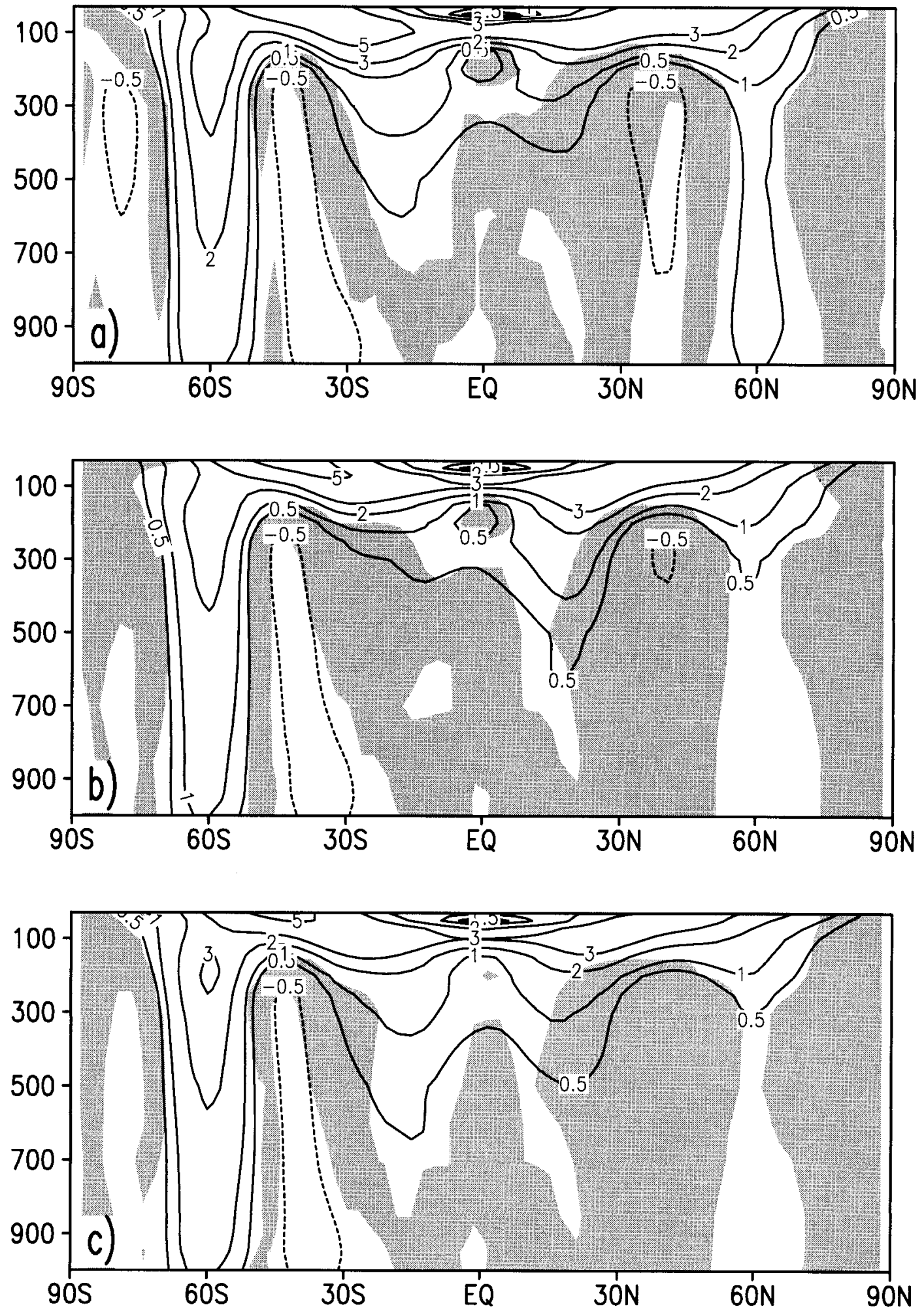

FIG. 13. Latitude-height cross sections of changes in annual zonal-mean zonal wind for the period (2030-50) compared to the CTL mean. The height coordinate is pressure in $\mathrm{hPa}$. Nonshaded areas indicate significance at the $95 \%$ level according to a Student's $t$-test. Contour spacing $\pm 0,0.5,1,2,3,5,10, \ldots \mathrm{m} \mathrm{s}^{-1}$ : (a) GHG $-\mathrm{CTL}$, (b) GSD - CTL, (c) GSDIO - CTL. 

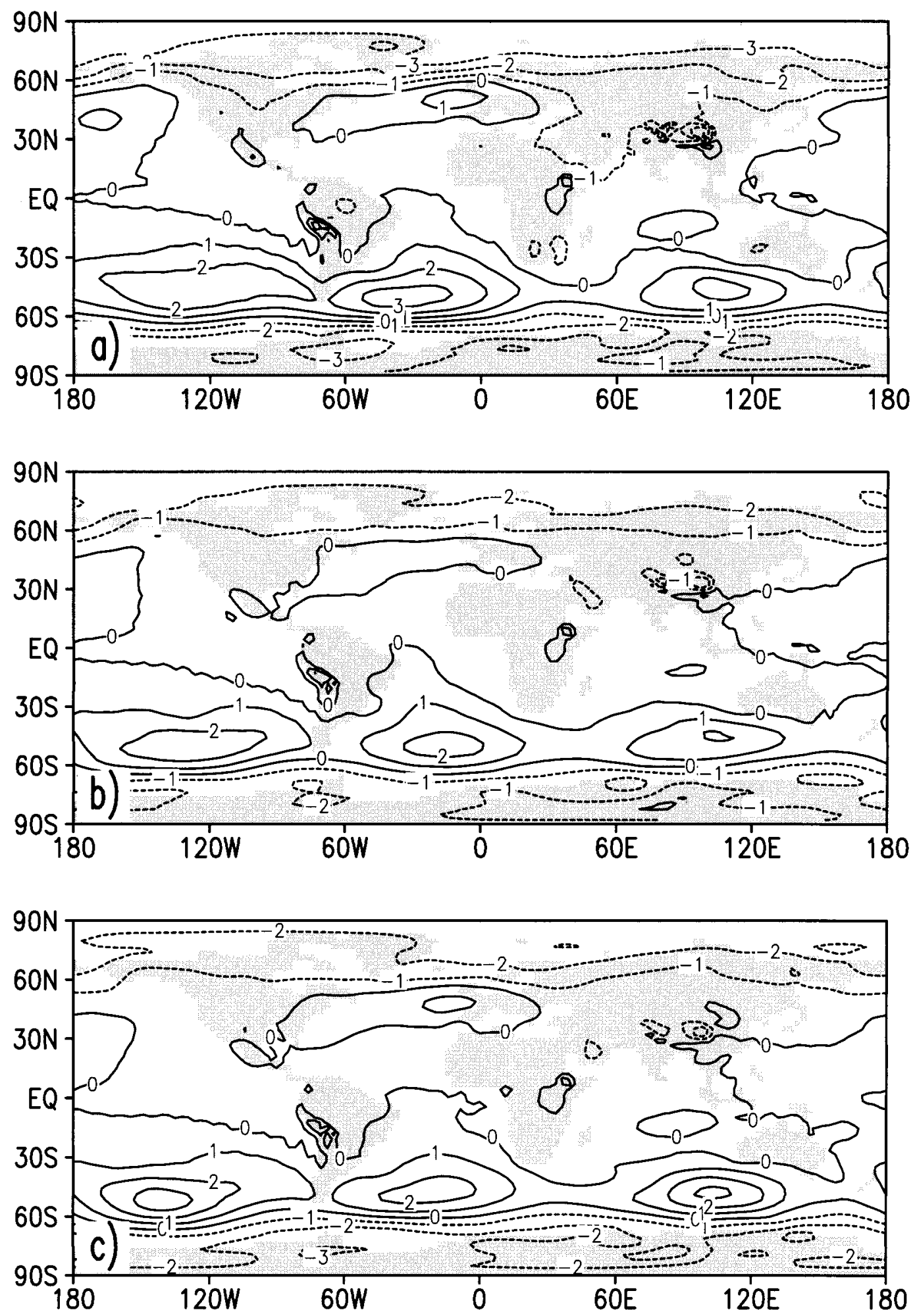

FIG. 14. Changes in annual mean sea level pressure for the period (2030-50) compared to the CTL mean. Contour spacing 1 hPa: (a) GHG - CTL, (b) GSD - CTL, (c) GSDIO - CTL. 
TABLE 4. Global annual mean water fluxes in the control experiment (CTL) and differences between perturbation and CTL in percent of CTL. The changes are normalized with the respective changes in surface air temperature. The changes refer to the decade (2040-50) compared to the 300 y means of CTL. In brackets: GHG changes for the decade 2090-2100.

\begin{tabular}{|c|c|c|c|c|}
\hline & $\begin{array}{c}\text { CTL } \\
\text { mm day }^{-1}\end{array}$ & $\begin{array}{c}\text { GHG - CTL } \\
\left(\%{ }^{\circ} \mathrm{C}^{-1}\right)\end{array}$ & $\begin{array}{c}\text { GSD - CTL } \\
\left(\%{ }^{\circ} \mathrm{C}^{-1}\right)\end{array}$ & $\begin{array}{c}\text { GSDIO - CTL } \\
\left(\%{ }^{\circ} \mathrm{C}^{-1}\right)\end{array}$ \\
\hline \multicolumn{5}{|l|}{ Globe } \\
\hline Precipitation & 2.81 & $0.68(0.70)$ & 0.27 & -0.36 \\
\hline Evaporation & 2.82 & $0.71(0.72)$ & 0.28 & -0.34 \\
\hline Surface air temp. $\left({ }^{\circ} \mathrm{C}\right)$ & 14.63 & $2.39(3.82)$ & 1.87 & 1.47 \\
\hline \multicolumn{5}{|l|}{ Sea } \\
\hline Precipitation & 3.09 & $-0.02(0.06)$ & -0.52 & -1.25 \\
\hline Evaporation & 3.39 & $0.65(0.66)$ & 0.20 & -0.69 \\
\hline Evaporation-precipitation & 0.30 & $7.63(6.81)$ & 7.63 & 5.16 \\
\hline Surface air temp. $\left({ }^{\circ} \mathrm{C}\right)$ & 17.10 & $1.90(3.01)$ & 1.50 & 1.11 \\
\hline \multicolumn{5}{|l|}{ Land } \\
\hline Precipitation & 2.13 & $2.10(1.97)$ & 1.80 & 1.08 \\
\hline Evaporation & 1.43 & $1.22(1.26)$ & 0.70 & 0.54 \\
\hline Runoff & 0.66 & $3.91(3.34)$ & 3.93 & 2.20 \\
\hline Snow on glaciers & 0.05 & $4.50(4.88)$ & 5.12 & 1.73 \\
\hline Surface air temp. $\left({ }^{\circ} \mathrm{C}\right)$ & 8.49 & $3.63(5.85)$ & 2.79 & 2.36 \\
\hline
\end{tabular}

ical Atlantic is caused by an eastward shift of the Walker circulation resulting in anomalous subsidence in these regions. As will be shown in a separate study, this drying contributes to a stabilization of the thermohaline circulation in the North Atlantic via anomalous transfer of freshwater, $\Delta(\mathrm{E}-\mathrm{P})>0$, from the Atlantic to the Pacific Ocean. In the Pacific and Indian Ocean, precipitation increases along the equator. The dipole in the Indian Ocean is due to a northward shift of the climatological (CTL) precipitation pattern. More precipitation than in CTL is simulated over large parts of Africa, especially in the Sahel region, over India, and also at high latitudes. Less precipitation than in CTL is simulated over the western parts of the United States and over southern Europe. With aerosols included, the changes are broadly similar as in GHG, but less intense. This differs from previous studies where the inclusion of aerosols was shown to weaken the Asian summer monsoon due to a strong direct aerosol forcing over land (Lal et al. 1995; Meehl et al. 1996a; Mitchell and Johns 1997). In our simulations, the direct effect is relatively small while the indirect effect, in contrast to the study of Meehl et al. (1996a), is more efficient over sea (cf. section 5).

In most models (as summarized in IPCC 1996), climate warming is associated with summer dryness in northern midlatitudes. As shown in Fig. 17, this also applies to our simulations, which show widespread soil drying during summer [June-August (JJA)] in northern middle and high latitudes. Farther south, most evident over India and North Africa (in terms of percentage change), the soil is moister than in CTL. The effect of the aerosols is to mitigate the GHG pattern. The dipole over South America has little seasonal dependence and is a stable feature in all experiments. As noted earlier, this pattern is forced, primarily, by the El Niño-like response in SST and precipitation. The effect of the aerosols can be seen more clearly in Fig. 18b, which shows the JJA changes in zonal-mean (land only) soil moisture. In GSD and GSDIO, the drying north of about $40^{\circ} \mathrm{N}$ is somewhat smaller than in GHG. According to Fig. 18a, these changes in soil moisture cannot be explained by changes in precipitation alone. At middle and high latitudes, changes in evaporation become important already in spring (Wetherald and Manabe 1995). North of $40^{\circ} \mathrm{N}$, there is more evaporation in GHG than in CTL, while there is hardly any change in GSD and even a slight negative one in GSDIO (not shown). At lower latitudes, the increase in soil moisture is predominantly due to enhanced moisture convergence, $\Delta(\mathrm{P}-$ E) $>0$, while the increase in evaporation (not shown) is relatively small at these latitudes.

As in most models (cf. IPCC 1996), there is a widespread reduction in diurnal temperature range (DTR) in our model simulations. Changes in DTR are due to diurnally asymmetric changes in the surface fluxes resulting from changes in atmospheric composition (e.g., water vapor, clouds, and aerosols) and soil moisture. As suggested by Stenchikov and Robock (1995), a contribution to the observed DTR decrease in the last $50 \mathrm{yr}$ (IPCC 1992; Karl et al. 1993) may be expected from increased solar (near-infrared) water vapor absorption in a warmer and therefore moister atmosphere. Stenchikov and Robock were able to isolate the water vapor effect on DTR change in 1D model simulations with fixed clouds. Indirectly, such an effect can also be identified in our model simulations. In GHG, for example, the larger water vapor abundance in the warmer climate ( $+20 \%$ globally compared to CTL) causes enhanced clear-sky absorption of solar radiation within the atmosphere so that less solar radiation is available, during daytime, for heating the ground (cf. Table 3 ). However, on a regional scale, changes in DTR are predominantly linked to changes in cloud and soil moisture. As an example, Fig. 18c shows a pronounced DTR decrease at about $20^{\circ} \mathrm{N}$ as a result of a moister climate with more 

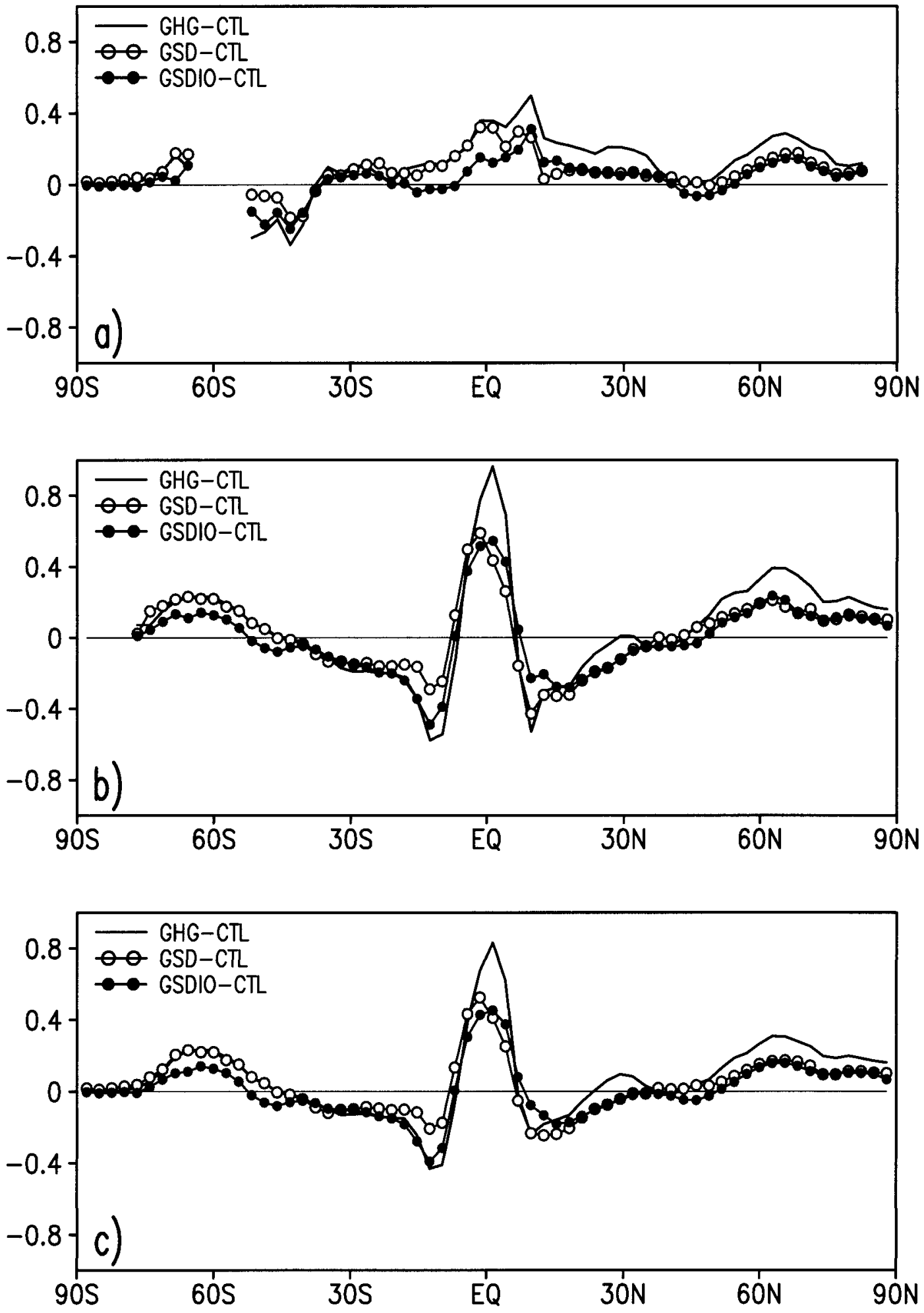

FIG. 15. Changes in annual zonal-mean precipitation for the period (2030-50) compared to the CTL mean. Units are mm day ${ }^{-1}$ : (a) land only, (b) sea only, (c) land and sea. 

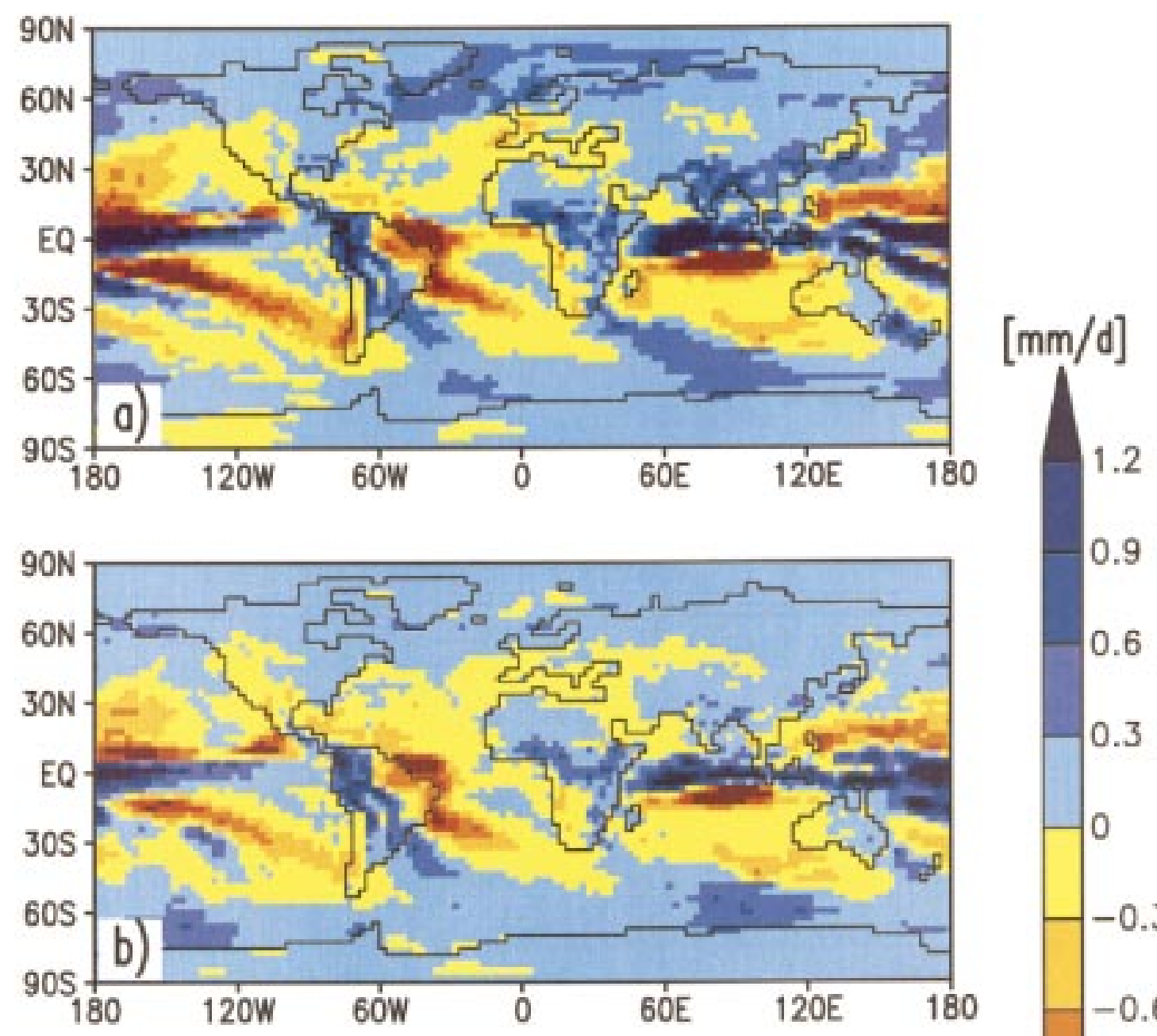

0.6
0.3

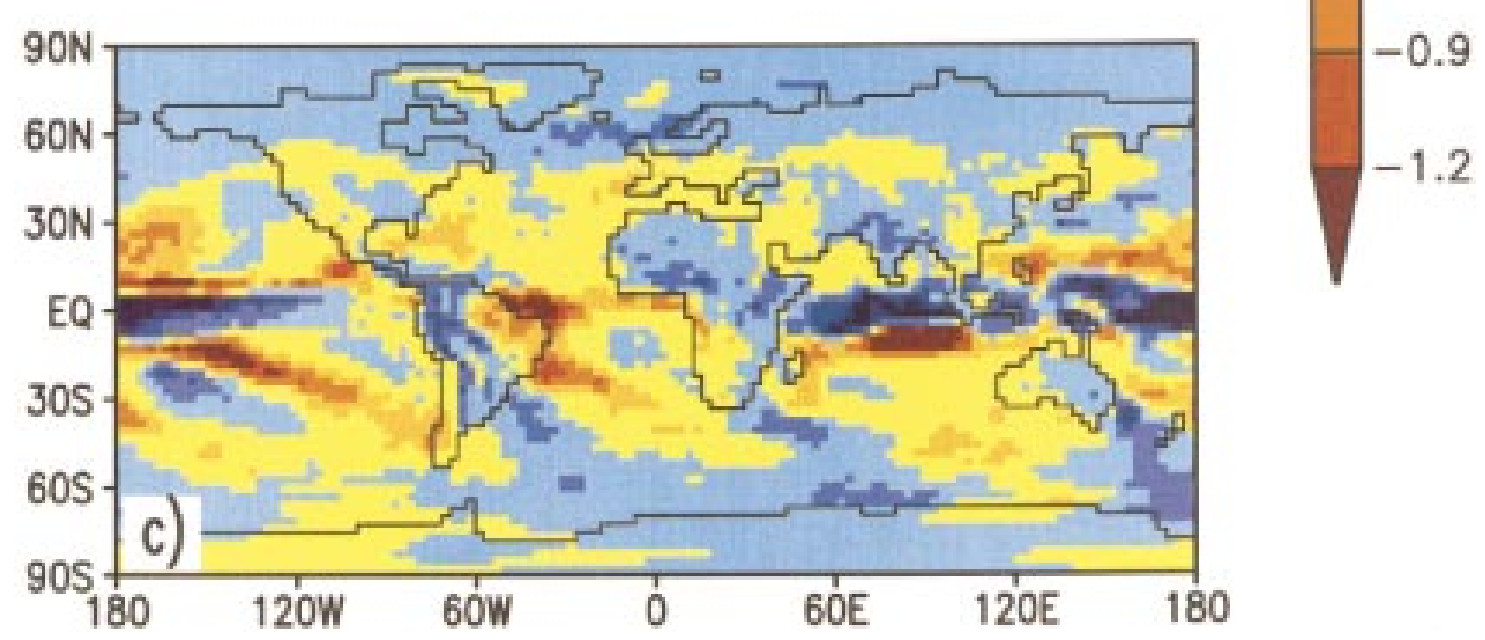

FIG. 16. Changes in annual mean precipitation for the period (2030-50) compared to the CTL mean. Units are mm day ${ }^{-1}$ : (a) GHG - CTL, (b) GSD - CTL, (c) GSDIO - CTL. 

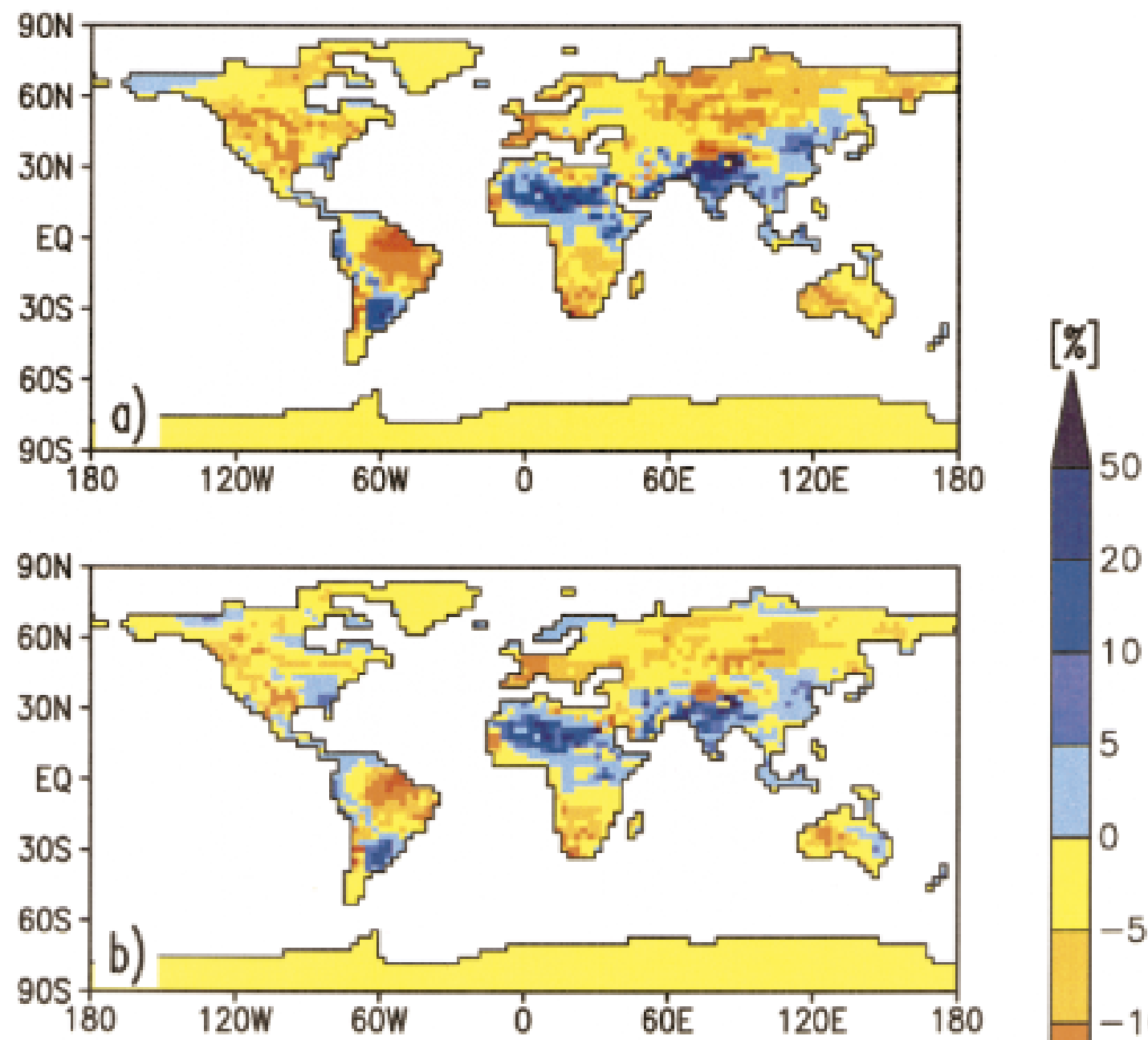

20

10

5
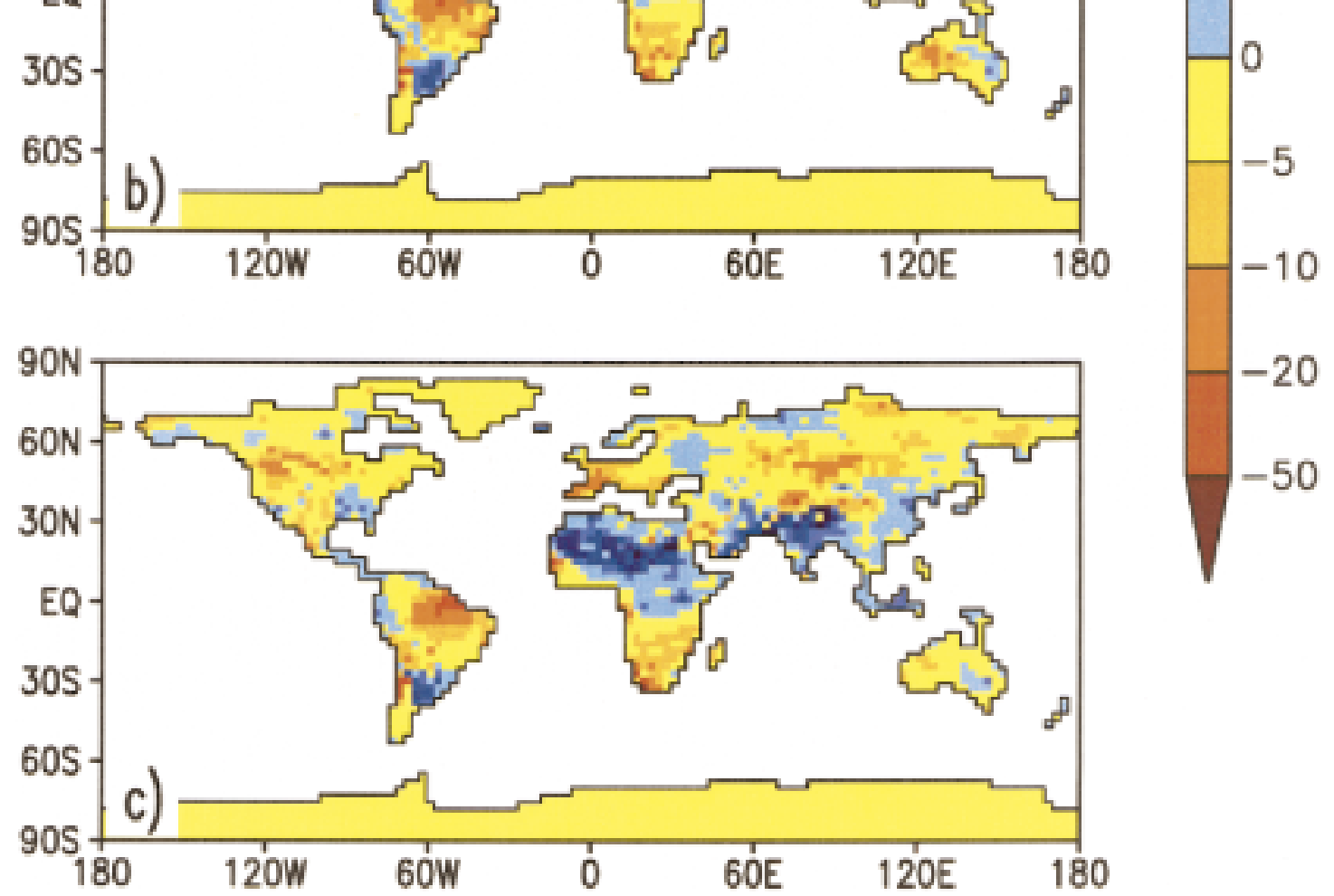

FIG. 17. Changes in seasonal mean (JJA) soil moisture for the period (2030-50) compared to the CTL mean. Units denote relative changes in percent of CTL: (a) $(\mathrm{GHG}-\mathrm{CTL}) / \mathrm{CTL} \times 100$, (b) $(\mathrm{GSD}-\mathrm{CTL}) / \mathrm{CTL} \times 100$, (c) $(\mathrm{GSDIO}-\mathrm{CTL}) /$ $\mathrm{CTL} \times 100$. 

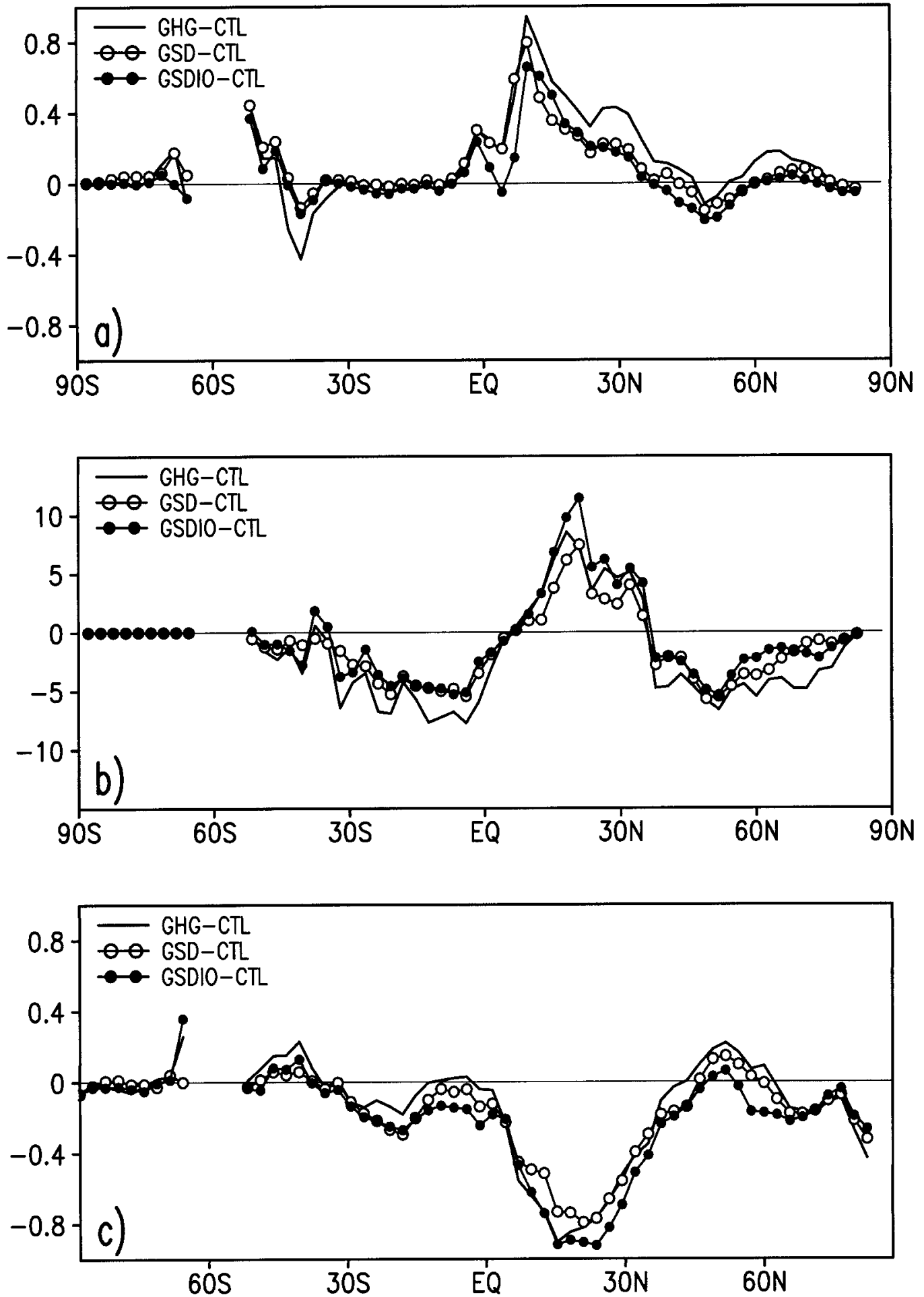

FIG. 18. Latitudinal profiles of zonal and seasonal mean (JJA) changes over land for the period (2030-50) compared to the CTL mean. (a) Precipitation in units of $\mathrm{mm} \mathrm{d}^{-1}$. (b) Soil moisture in units of percent change with respect to CTL mean. (c) Diurnal temperature range (DTR) in units of ${ }^{\circ} \mathrm{C}$. 
precipitation (Fig. 18a), more clouds (not shown), and a wetter surface (Fig. 18b). These changes tend to reduce the surface warming, more in the daytime than at night, due to reduced solar fluxes and enhanced evaporation. On the other hand, the DTR changes are small, and even positive sometimes, in regions where soil moisture is diminished (cf. Fig. 18b). The close correspondence between changes in DTR, cloud, and soil moisture can also be identified in the respective geographical distributions (not shown), while changes in water vapor are less correlated with those in DTR, except on the global scale.

The impact of increased aerosol forcing on DTR is twofold. First, due to radiative effects, less solar radiation reaches the surface so that DTR is expected to be smaller. On the other hand, the atmosphere becomes colder and drier so that more solar radiation reaches the surface and DTR is expected to become larger. Therefore, the net aerosol effect on DTR may be small (Hansen et al. 1995; Mitchell et al. 1995b; Stenchikov and Robock 1995). In our experiments, according to Fig. $18 \mathrm{c}$, the basic pattern is simulated already in GHG while the aerosols, at most latitudes, tend to enhance the amount of change. This is more evident in the experiment with both the direct and indirect effect included (GSDIO). However, one should realize that possible changes in precipitation formation and cloud lifetime, as a result of changing aerosol concentrations, are not included in the GSDIO experiment.

Although multiple realizations would have been preferable for assessing the stability of the response patterns, the striking similarity of the geographical distributions in the three experiments should give some confidence in the robustness of the results. The probability of a coincidental similarity of the response in three realizations with slightly different forcings is at least very low.

\section{Summary and concluding remarks}

In this study, we discuss the time-dependent climate response to changing concentrations of greenhouse gases and aerosols as simulated with a coupled GCM of the atmosphere and the ocean. The concentrations of the well-mixed greenhouse gases like $\mathrm{CO}_{2}, \mathrm{CH}_{4}, \mathrm{~N}_{2} \mathrm{O}$, and several industrial gases like the CFCs are prescribed as observed (1860-1990) and according to scenario IS92a thereafter. The space-time distribution of tropospheric ozone is prescribed, based on precalculated fields from simulations with an atmospheric chemistry model coupled to the same AGCM employed in this study. The tropospheric sulfur cycle is calculated within the coupled model using prescribed sulfur emissions of the past and projected until 2050 (IS92a). This approach allows us to estimate the space-time distribution of sulfate aerosol and the associated radiative forcing consistent with the dynamics and physics of the model. The ra- diative impact of the aerosols is considered via both the direct and the indirect (i.e., cloud albedo) effect.

The results of three climate perturbation experiments are compared with those obtained from an unforced 300yr control experiment. In the first perturbation experiment, only the well-mixed greenhouse gases like $\mathrm{CO}_{2}$ and others are allowed to change with time. In the second experiment, the direct sulfate aerosol forcing is included, in addition to that of the well-mixed greenhouse gases. The third experiment allows for changes in all of the components mentioned above, that is, well-mixed greenhouse gases, tropospheric ozone, direct and indirect aerosol effects.

As in previous experiments, increasing aerosol concentrations tend to mitigate greenhouse warming, and the aerosol effects are evident particularly over the Northern Hemisphere continents and the Arctic regions. In the global annual mean, the evolution of (low-pass filtered) temperature change follows the evolution in radiative forcing. On regional scales, such a good correspondence between radiative forcing and temperature response no longer occurs because heat transports in atmosphere and ocean and atmospheric feedbacks become important. In all experiments, there is a poleward shift of the midlatitude westerlies and SLP patterns. These shifts are most significant in the Southern Hemisphere. Here, the impact of the aerosols is rather small. In the Northern Hemisphere, the poleward shift is most pronounced in the greenhouse gas only experiment. Aerosol cooling tends to weaken the response so that one may conclude that the simulated changes in zonal wind and sea level pressure are predominantly governed by the amount of global warming.

This conclusion applies to precipitation as well. With aerosols included, the changes are broadly similar as in the greenhouse gas only experiment, but less intense. This differs from previous studies indicating that the inclusion of aerosols leads to a weakening of the Indian summer monsoon due to strong aerosol forcing over land. In our simulations, with and without aerosols, the Indian summer monsoon becomes stronger because the direct aerosol effect over land is relatively small while the indirect effect is more efficient over sea. Furthermore, in all experiments, more precipitation than in the control experiment is simulated at high latitudes and less precipitation is simulated over the western parts of the United States and over southern Europe. Over the oceans where changes in evaporation are comparatively small, the response patterns are largely forced dynamically. Precipitation is enhanced by anomalous moisture convergence in a narrow band along the equator while it is reduced in adjacent areas where moisture divergence prevails as a result of compensating subsidence. Also, many regional changes are due to changes in the dynamics. For example, the precipitation responses in the tropical Pacific and adjacent regions can be related to an El Niño-like SST warming pattern and an associated shift of the Walker circulation causing heavy pre- 
cipitation around the date line and subsidence drying over northeastern Brazil and the tropical Atlantic. These are typical features in all experiments.

Similar to previous experiments, there is summer drying over large parts of the Northern Hemisphere continents while precipitation intensifies in the monsoon regions and soils become wetter. Regional changes in soil moisture and clouds result in regional changes in the diurnal temperature range (DTR). On the global scale, predominantly, the reduction in DTR can also be related to increased absorption of solar radiation by water vapor in the warmer and moister atmosphere so that less solar radiation, during daytime, is available for heating the surface. The impact of the aerosols on DTR reduction is relatively small because aerosol cooling and, therefore, drying of the atmosphere tends to counteract the radiative effect of the aerosols.

In general, the climate response patterns obtained in the greenhouse gas only experiment are not changed in a fundamental way if aerosols are added. However, aerosols do significantly change the distribution of radiative heating between the atmosphere and the surface and, hence, the hydrological cycle. In the greenhouse gas only experiment, the changes in heat budget have the same sign as the "normal" flux distribution. While the atmosphere is cooled radiatively, the surface is warmed and the turbulent flux anomalies are directed upward. Including both the direct and the indirect effect, anomalous radiative heating of the atmosphere takes place while the surface is cooled radiatively so that the anomalous transfer of heat (both sensible and latent heat flux) is directed downward from the atmosphere to the surface. As a result, global mean evaporation and precipitation are reduced in a warmer climate through both direct and indirect aerosol effects.

Although the distribution of sulfate aerosols, their radiative effects, and the associated climate responses are estimated in an interactive and model-consistent way in this study, one has to note that the uncertainties are still very large. The main sources of uncertainty are the history of anthropogenic sulfur emissions and model simplifications, not only in the sulfur cycle model, but also in the driving GCM. In particular, the radiative properties of aerosols are prescribed in an idealized manner, the aerosol-cloud effects are deduced from empirical relationships between cloud droplet number concentrations and aerosol mass, and nonsulfate aerosols are neglected. Finally, future projections of short-lived substances like tropospheric aerosols are very uncertain because emission controls, which would be much more immediately effective than for long-lived greenhouse gases like $\mathrm{CO}_{2}$, are difficult to foresee.

Acknowledgments. We thank Geert-Jan Roelofs for providing the results of the tropospheric ozone simulations. David Parker made available to us the observed temperature record, Ulf Hansson the anthropogenic sulfur emissions, and Martin Heimann the historical record of greenhouse gas concentrations. We gratefully acknowledge the assistance of Monika Esch and Ulrich Schlese, who adapted the model code for the various experiments and supervised the simulations. We thank Olaf Esher and Norbert Noreiks for drawing the figures. This research was supported by the German Government under Contract 07VKV01/1 and by the European Community under Contract ENV4-CT95-0099 (SINDICATE). The model simulations were performed at the German Climate Computer Center in Hamburg (DKRZ).

\section{APPENDIX}

\section{Specification of Greenhouse Gas Concentrations in the Experiments}

\section{a. Initial concentrations}

While the concentrations of the industrial gases (CFCs etc.) are correctly set to zero in the beginning (1860) of the transient experiments GHG, GSD, and GSDIO, the initial concentrations of $\mathrm{CO}_{2}, \mathrm{CH}_{4}$, and $\mathrm{N}_{2} \mathrm{O}$ do not correspond to the observed concentrations $\left[C^{0}=C(1860)\right]$ but to those observed in 1990, as prescribed in the CTL experiment $\left[C_{m}^{0}=C(1990)=C_{\mathrm{ctl}}\right]$. This difference in the initial concentrations $\left(C_{m}^{0}-C^{0}\right)$ has to be taken into account when constructing the time series of the model concentrations $C_{m}(t)$ from the original, that is, observed and IS92a projected, record $C(t)$, where $t$ is time. The aim is to prescribe $C_{m}(t)$ in a way that the radiative forcing $F(t)$ obtained from the original record $C^{0}, C(t)$ can also be reproduced from the model record $C_{m}^{0}, C_{m}(t)$. The corrections are derived from approximations of the radiative forcing as a function of concentration (IPCC 1990, their Table 2.2). In the following, time $(t)$ is omitted for convenience.

For $\mathrm{CO}_{2}$, the logarithmic dependency of the forcing on concentration is well established, $F=a \ln \left(C / C^{0}\right)=$ $a \ln \left(C_{m} / C_{m}^{0}\right)$, where $a$ is a constant, so that $C_{m}=$ $C\left(C_{m}^{0} / C^{0}\right)$. Similarly, the forcing for $\mathrm{CH}_{4}$ and $\mathrm{N}_{2} \mathrm{O}$ can be approximated, with $b=$ const, as $F=b\left[(C)^{1 / 2}-\right.$ $\left.\left(C^{0}\right)^{1 / 2}\right]=b\left[\left(C_{m}\right)^{1 / 2}-\left(C_{m}^{0}\right)^{1 / 2}\right]$, so that $\left(C_{m}\right)^{1 / 2}=(C)^{1 / 2}$ $-\left(C^{0}\right)^{1 / 2}+\left(C_{m}^{0}\right)^{1 / 2}$.

\section{b. Bias correction of the radiation code}

The expressions of the radiative forcings shown above include constants $a, b$, which are estimated in IPCC (1990) according to $a\left(\mathrm{CO}_{2}\right)=6.3, b\left(\mathrm{CH}_{4}\right)=$ 0.031 and $b\left(\mathrm{~N}_{2} 0\right)=0.14$. From a series of forcing tests over a wide range of concentrations, from preindustrial to future, it was found that the ECHAM4 radiation code significantly underestimates the $\mathrm{CO}_{2}$ forcing $\left(a \rightarrow a^{*}\right.$ $\sim 5.5$ ). A similar result was obtained by Cess et al. (1993), who found that broadband radiation codes typically used in GCMs underestimate the $2 \times \mathrm{CO}_{2}$ forcing, compared to line-by-line radiation codes, by up to $20 \%$. We also found an underestimate for $\mathrm{N}_{2} \mathrm{O}\left(b \rightarrow b^{*} \sim\right.$ 
TABLE A1. Comparison of IPCC and ECHAM-4 radiative forcing $\left(\mathrm{W} \mathrm{m}^{-2}\right)$.

\begin{tabular}{|c|c|c|c|c|c|c|}
\hline Years and sources & $\mathrm{CO}_{2}$ & $\mathrm{CH}_{4}$ & $\mathrm{~N}_{2} \mathrm{O}$ & CFC's & Sum $^{\mathrm{a}}$ & $\begin{array}{c}\text { Total, i.e., } \\
\text { including } \\
\text { band overlap }\end{array}$ \\
\hline \multicolumn{7}{|l|}{$1750-1990$} \\
\hline IPCC (1995) & 1.56 & 0.47 & 0.14 & 0.28 & 2.45 & 2.45 \\
\hline ECHAM-4 & 1.55 & 0.57 & 0.15 & 0.30 & 2.57 & 2.56 \\
\hline \multicolumn{7}{|l|}{${ }^{\mathrm{b}} E C H A M-4$} \\
\hline $1750-1860$ & 0.18 & 0.10 & 0.02 & 0.00 & 0.30 & 0.30 \\
\hline $1860-1990$ & 1.37 & 0.47 & 0.13 & 0.30 & 2.27 & 2.26 \\
\hline \multicolumn{7}{|l|}{ 1990-2100 (IS92a) } \\
\hline IPCC (1995) & 4.50 & 0.76 & 0.37 & 0.15 & 5.78 & 5.78 \\
\hline ECHAM-4 & 4.72 & 0.69 & 0.40 & $0.10^{\mathrm{c}}$ & 5.91 & 5.86 \\
\hline
\end{tabular}

a In IPCC, overlap is included already in the individual components.

b Year 1860: Start of the scenario experiments.

c Updated (Copenhagen-like) CFC-scenario according to IPCC (1996).

0.09) in the ECHAM4 code, while the $\mathrm{CH}_{4}$ forcing errors are less systematic and the total forcing of the industrial gases is in reasonable agreement with IPCC estimates. To eliminate the biases, the original concentrations $C$ are corrected in a way that the model is able to compute the "correct" (IPCC) forcing despite the fact that the ECHAM4 constants $a^{*}, b^{*}$ differ from the respective IPCC estimates $a, b$. The corrected concentrations $C^{*}$ are derived again from the simple radiative forcing formulations applied in section a.

For the $\mathrm{CO}_{2}$ forcing we require $F=a \ln \left(C / C^{0}\right)=$ $a^{*} \ln \left(C^{*} / C^{0}\right)$, so that $C^{*}=C^{0} \exp \left[\left(a / a^{*}\right) \ln \left(C / C^{0}\right)\right]$. Analogously, for the $\mathrm{N}_{2} \mathrm{O}$ forcing we require $F=$ $b\left[(C)^{1 / 2}-\left(C^{0}\right)^{1 / 2}\right]=b^{*}\left[\left(C^{*}\right)^{1 / 2}-\left(C^{0}\right)^{1 / 2}\right]$, so that $C^{*}$ $=\left\{\left(b / b^{*}\right)\left[(C)^{1 / 2}-\left(C^{0}\right)^{1 / 2}\right]+\left(C^{0}\right)^{1 / 2}\right\}^{2}$.

\section{c. Concentrations of $\mathrm{CO}_{2}, \mathrm{CH}_{4}$, and $\mathrm{N}_{2} \mathrm{O}$ used in experiments $G H G, G S D$, and $G S D I O$}

By combining sections $\mathrm{a}$ and $\mathrm{b}$ we obtain the concentrations $C_{m}^{*}=C_{m}^{*}(t)$, which are used in the timedependent forcing experiments,

$$
\begin{aligned}
& C_{m}^{*}=C_{m}^{0} \exp \left[a / a^{*} \ln \left(C / C^{0}\right)\right], \\
& \quad \text { with } a / a^{*}=1.15 \text { for } \mathrm{CO}_{2}, \text { and } \\
& C_{m}^{*}=\left\{b / b^{*}\left[(C)^{1 / 2}-\left(C^{0}\right)^{1 / 2}\right]+\left(C_{m}^{0}\right)^{1 / 2}\right\}^{2}, \\
& \text { with } b / b^{*}=1.5 \text { for } \mathrm{N}_{2} \mathrm{O} \text { and } b / b^{*}=1 \text { for } \mathrm{CH}_{4} .
\end{aligned}
$$

Here, $C=C(t)$ is the original record of concentrations, observed and IS92a projected, $C^{0}$ is the respective concentration as observed in 1860 , and $C_{m}^{0}$ is the initial (nominally 1860, but actually 1990) concentration prescribed in the experiments.

No corrections whatsoever are made for ozone and for the industrial gases (CFCs etc.).

Table A1 confirms that the resulting ECHAM4 forcings are in reasonable agreement with the corresponding IPCC estimates.

\section{REFERENCES}

Albrecht, B. A., 1989: Aerosols, cloud microphysics, and fractional cloudiness. Science, 245, 1227-1230.

Bacher, A., J. M. Oberhuber, and E. Roeckner, 1998: ENSO dynamics and seasonal cycle in the tropical Pacific as simulated by the ECHAM4/OPYC3 coupled general circulation model. Climate Dyn., 14, 431-450.

Bengtsson, L., E. Roeckner, and M. Stendel, 1999: Why is the global warming proceeding much slower than expected? J. Geophys. Res., 104, 3865-3876.

Berntsen, T. K., I. S. A. Isaksen, G. Myhre, J. S. Fuglestvedt, F. Stordal, T. A. Larsen, R. S. Freckleton, and K. P. Shine, 1997: Effects of anthropogenic emissions on tropospheric ozone and its radiative forcing. J. Geophys. Res., 102, 28 101-28 126.

Boer, G. J., 1993: Climate change and the regulation of the surface moisture and energy budgets. Climate Dyn., 8, 225-239.

Brinkop, S., and E. Roeckner, 1995: Sensitivity of a general circulation model to parameterizations of cloud-turbulence interactions in the atmospheric boundary layer. Tellus, 47A, 197-220.

Cess, R. D., and Coauthors, 1993: Uncertainties in carbon dioxide radiative forcing in atmospheric general circulation models. Science, 262, 1252-1255.

Charlson, R. J., J. Langner, H. Rodhe, C. B. Leovy, and S. G. Warren, 1991: Perturbation of the Northern Hemisphere radiative balance by backscattering from anthropogenic sulfate aerosols. Tellus, 43AB, 152-163.

Erickson, D. J., III, R. J. Oglesby, and S. Marshall, 1995: Climate response to indirect anthropogenic sulfate forcing. Geophys. Res. Lett., 22, 2017-2020.

Feichter, J., E. Kjellström, H. Rodhe, F. Dentener, J. Lelieveld, and G. J. Roelofs, 1996: Simulation of the tropospheric sulfur cycle in a global climate model. Atmos. Environ., 30, 1693-1707.

—, U. Lohmann, and I. Schult, 1997: The atmospheric sulfur cycle and its impact on the shortwave radiation. Climate Dyn., 13, $235-246$.

Fouquart, Y., and B. Bonnel, 1980: Computations of solar heating of the Earth's atmosphere: A new parameterization. Beitr. Phys. Atmos., 53, 35-62.

Gloersen, P., W. J. Campbell, D. J. Cavalieri, J. C. Comiso, C. L. Parkinson, and H. J. Zwally, 1992: Arctic and Antarctic Sea Ice, 1978-1987: Satellite passive-microwave observations and analysis. National Aeronautics and Space Administration, NASA SP511, $290 \mathrm{pp}$

Hansen, J., E., M. Sato, and R. Ruedy, 1995: Long term changes of the diurnal cycle: Implications about mechanisms of global climate change. Atmos. Res., 37, 175-209.

Hao, W. M., M. H. Liu, and P. J. Crutzen, 1990: Estimates of Annual and Regional Releases of $\mathrm{CO}_{2}$ and other Trace Gases to the Atmosphere from Fires in the Tropics. Springer-Verlag, 440462.

Hasselmann, K., and Coauthors, 1995: Detection of anthropogenic climate-change using a fingerprint method. Max-Planck-Institut für Meteorologie, Rep. 168, 20 pp. [Available from MPI für Meteorologie, Bundesstr. 55, 20146 Hamburg, Germany.]

Haywood, J. M., and K. P. Shine, 1995: The effect of anthropogenic sulfate and soot aerosol on the clear sky planetary radiation budget. Geophys. Res. Lett., 22, 603-606.

_ R. J. Stouffer, R. T. Wetherald, S. Manabe, and V. Ramaswamy, 1997: Transient response of a coupled model to estimated changes in greenhouse gas and sulfate concentrations. Geophys. Res. Lett., 24, 1335-1338.

Hegerl, G. C., K. Hasselmann, U. Cubasch, J. F. B. Mitchell, E. Roeckner, R. Voss, and J. Waszkewitz, 1997: Multi-fingerprint detection and attribution analysis of greenhouse gas, greenhouse gas-plus-aerosol and solar forced climate change. Climate Dyn., 13, 613-634.

IPCC, 1990: Scientific Assessment of Climate Change. J. T. Houghton, G. J. Jenkins, and J. J. Ephraums, Eds., Cambridge University Press, 365 pp. 
1992: Climate Change 1992: The Supplementary Report to the IPCC Scientific Assessment. J. T. Houghton, B. A. Callendar, and S. K. Varney, Eds., Cambridge University Press, 198 pp.

_ 1996: Climate Change 1995. The Science of Climate Change. J. T. Houghton, L. G. Meira Filho, B. A. Callendar, N. Harris, A. Kattenberg, and K. Maskell, Eds., Cambridge University Press, $572 \mathrm{pp}$

Johns, T. C., R. E. Carnell, J. F. Crossley, J. M. Gregory, J. F. B. Mitchell, C. A. Senior, S. F. B. Tett, and R. A. Wood, 1997: The second Hadley Centre Coupled Model: Description, spinup and validation. Climate Dyn., 13, 103-134.

Johnson, D. W., 1993: Parameterisation of the cloud topped boundary layer: Aircraft Measurements. Proc. ECMWF Workshop on Parameterization of the Cloud Topped Boundary Layer, European Centre for Medium-Range Weather Forecasts, Reading, United Kingdom, 77-117.

Karl, T. R., and Coauthors, 1993: Asymmetric trends of daily maximum and minimum temperature. Bull. Amer. Meteor. Soc., 74, $1718-1723$.

Kiehl, J. T., and B. P. Briegleb, 1993: The relative roles of sulfate aerosols and greenhouse gases in climate forcing. Science, $\mathbf{2 6 0}$, 311-314.

Köpke, P., M. Hess, I. Schult, and E. P. Shettle, 1997: Global aerosol dataset. Max-Planck-Institut für Meteorologie, Rep. 243, 44 pp. [Available from MPI für Meteorologie, Bundesstr. 55, 20146 Hamburg, Germany.]

Lal, M., U. Cubasch, R. Voss, and J. Waszkewitz, 1995: Effect of transient increase in greenhouse gases and sulphate aerosols on monsoon climate. Current Sci., 69, 752-763.

Langner, J., and H. Rodhe, 1991: A global three-dimensional model of the tropospheric sulfur cycle. J. Atmos. Chem., 13, 225-263.

Legrand, M., 1995: Atmospheric chemistry changes versus past climate inferred from polar ice cores. Aerosol Forcing of Climate. R. J. Charlson and J. Heintzenberg, Eds., John Wiley and Sons, 123-151.

Le Treut, H., M. Forichon, O. Boucher, and Z. X. Li, 1996: Aerosols and greenhouse gases forcing: Cloud feedbacks associated to the climate response. Physical Mechanisms and Their Validation, H. Le Treut, Ed., NATO ASI Series, Vol. 1 (34), Springer-Verlag, $267-280$

Lohmann, U., and J. Feichter, 1997: Impact of sulfate aerosols on albedo and lifetime of clouds: A sensitivity study with the ECHAM4 GCM. J. Geophys. Res., 102, 13 685-13 700.

Louis, J. F., 1979: A parametric model of vertical eddy fluxes in the atmosphere. Bound.-Layer Meteor., 17, 187-202.

Manabe, S., R. J. Stouffer, M. J. Spelman, and K. Bryan, 1991: Transient responses of a coupled ocean-atmosphere model to gradual changes of atmospheric $\mathrm{CO}_{2}$. Part I: Annual mean response. J. Climate, 4, 785-818.

Meehl, G. A., and W. M. Washington, 1996: El Niño-like climate change in a model with increased atmospheric $\mathrm{CO}_{2}$ concentrations. Nature, 382, 56-60

$\longrightarrow,-$ D. J. Erickson III, B. P. Briegleb, and P. J. Jaumann, 1996: Climate change from increased $\mathrm{CO}_{2}$ and direct and indirect effects of sulfate aerosols. Geophys. Res. Lett., 23, 3755-3758.

Miller, M. J., T. N. Palmer, and R. Swinbank, 1989: Parameterization and influence of sub-grid scale orography in general circulation and numerical weather prediction models. Meteor. Atmos. Phys., 40, 84-109.

Mitchell, J. F. B., and T. J. Johns, 1997: On the modification of greenhouse gas warming by sulphate aerosols. J. Climate, 10, 245-267.

,-- J. M. Gregory, and S. F. B. Tett, 1995a: Transient climate response to increasing sulphate aerosols and greenhouse gases. Nature, 376, 501-504.

— R. A. Davies, W. J. Ingram, and C. A. Senior, 1995b: On surface temperature, greenhouse gases, and aerosols: Models and observations. J. Climate, 8, 2364-2386.

Morcrette, J.-J., L. Smith, and Y. Fouquart, 1986: Pressure and tem- perature dependence of the absorption in longwave radiation parameterizations. Beitr. Phys. Atmos., 59, 455-469.

Nordeng, T. E., 1994: Extended versions of the convective parameterization scheme at ECMWF and their impact on the mean and transient activity of the model in the Tropics. ECMWF Research Department, Tech. Memo. No. 206, European Centre for Medium-Range Weather Forecasts, 41 pp. [Available from ECMWF, Shinfield Park, Reading, Berkshire RG2 9AX, United Kingdom.]

Oberhuber, J. M., 1993: Simulation of the Atlantic circulation with a coupled sea ice-mixed layer-isopycnal general circulation model. Part I: Model description. J. Phys. Oceanogr., 23, 808829.

Örn, G., U. Hansson, and H. Rodhe, 1996: Historical worldwide emissions of anthropogenic sulfur: 1860-1985. Rep. CM-91, Dept. of Meteorology, Stockholm University, and International Meteorological Institute, Stockholm, Sweden, 20 pp. [Available from Library, Dept. of Meteorology, Stockholm University, S10691 Stockholm, Sweden.]

Penner, J. E., R. E. Dickinson, and C. A. O'Neill, 1992: Effects of aerosol from biomass burning on the global radiation budget. Science, 256, 1432-1433.

Ramaswamy, V., M. D. Schwarzkopf, and W. J. Randel, 1996: Fingerprint of ozone depletion in the spatial and temporal pattern of recent lower-stratospheric cooling. Nature, 382, 616-618.

Raval, A., and V. Ramanathan, 1989: Observational determination of the greenhouse effect. Nature, 342, 758-762.

Rockel, B., E. Raschke, and B. Weyres, 1991: A parameterization of broad band radiative transfer properties of water, ice and mixed clouds. Beitr. Phys. Atmos., 64, 1-12.

Roeckner, E., 1995: Parameterization of cloud radiative properties in the ECHAM4 model. Proc. WCRP Workshop on Cloud Microphysics Parameterizations in Global Atmospheric Circulation Models, Kananaskis, AB, Canada, WCRP, 105-116.

_, T. Siebert, and J. Feichter, 1995: Climatic response to anthropogenic sulfate forcing simulated with a general circulation model. Aerosol Forcing of Climate. R. J. Charlson and J. Heintzenberg, Eds., John Wiley and Sons, 349-362.

— model ECHAM-4: Model description and simulation of presentday climate. Max-Planck-Institut für Meteorologie, Rep. 218, 90 pp. [Available from MPI für Meteorologie, Bundesstr. 55, 20146 Hamburg, Germany.]

- J. M. Oberhuber, A. Bacher, M. Christoph, and I. Kirchner, 1996b: ENSO variability and atmospheric response in a global coupled atmosphere-ocean GCM. Climate Dyn., 12, 737-754.

Roelofs, G.-J., and J. Lelieveld, 1995: Distribution and budget of $\mathrm{O}_{3}$ in the troposphere calculated with a chemistry general circulation model. J. Geophys. Res., 100, 20 983-20 998.

, — - and J. Feichter, 1998: Model simulations of the changing distribution of tropospheric ozone and its radiative forcing of climate: Past, present, and future. Max-Planck-Institut für Meteorologie, Rep. 283, 24 pp. [Available from MPI für Meteorologie, Bundesstr. 55, 20146 Hamburg, Germany.]

Schult, I., J. Feichter, and W. F. Cooke, 1997: The effect of black carbon and sulfate aerosols on the global radiation budget. $J$. Geophys. Res., 102, 30 107-30118.

Spiro, P. A., D. J. Jacob, and J. A. Logan, 1992: Global inventory of sulfur emissions with $1 \mathrm{deg} \times 1 \mathrm{deg}$ resolution. J. Geophys. Res., 97, 6023-6036.

Stenchikov, G. L., and A. Robock, 1995: Diurnal asymmetry of climatic response to increased $\mathrm{CO}_{2}$ and aerosols: Forcing and feedbacks. J. Geophys. Res., 100, 26 211-26 227.

Taylor, K., and J. E. Penner, 1994: Response of the climate system to atmospheric aerosols and greenhouse gases. Nature, $\mathbf{3 6 9}, \mathbf{7 3 4}$ 737.

Tegen, I., A. A. Lacis, and I. Fung, 1996: The influence on climate forcing of mineral aerosols from disturbed soils. Nature, 380, 419-422.

Tiedtke, M., 1989: A comprehensive mass flux scheme for cumulus parameterization in large-scale models. Mon. Wea. Rev., 117, $1779-1800$ 
Timmermann, A., J. Oberhuber, A. Bacher, M. Esch, M. Latif, and E. Roeckner, 1999: ENSO response to greenhouse warming. $\mathrm{Na}$ ture, 398, 694-697.

Twomey, S. A., 1977: The influence of pollution on the short-wave albedo of clouds. J. Atmos. Sci., 34, 1149-1152.
Wetherald, R. T., and S. Manabe, 1995: The mechanisms of summer dryness induced by greenhouse warming. J. Climate, 8, 30963108.

Williamson, D. L., and P. J. Rasch, 1994: Water vapor transport in the NCAR CCM2. Tellus, 46A, 34-51. 